San Jose State University

SJSU ScholarWorks

Doctoral Projects

Master's Theses and Graduate Research

Spring 5-1-2015

\title{
The Effectiveness of a Standardized Positioning Tools and Bedside Education on the Developmental Positioning Proficiency of NICU Nurses
}

Arlene Spilker

Northern California Consortium, Doctor of Nursing Practice Program, California State University, Fresno and San José State University

Follow this and additional works at: https://scholarworks.sjsu.edu/etd_doctoral

Part of the Critical Care Nursing Commons

\section{Recommended Citation}

Spilker, Arlene, "The Effectiveness of a Standardized Positioning Tools and Bedside Education on the Developmental Positioning Proficiency of NICU Nurses" (2015). Doctoral Projects. 4.

DOI: https://doi.org/10.31979/etd.t2z4-7379

https://scholarworks.sjsu.edu/etd_doctoral/4

This Doctoral Project is brought to you for free and open access by the Master's Theses and Graduate Research at SJSU ScholarWorks. It has been accepted for inclusion in Doctoral Projects by an authorized administrator of SJSU ScholarWorks. For more information, please contact scholarworks@sjsu.edu. 


\section{THE EFFECTIVENESS OF A STANDARDIZED POSITIONING TOOL AND BEDSIDE EDUCATION ON THE DEVELOPMENTAL POSITIONING PROFICIENCY OF NICU NURSES}

Developmental positioning for preterm infants is an essential skill for neonatal intensive care unit (NICU) nurses. The benefits of developmental positioning are evident in the literature, but less is known about how NICU nurses learn about developmental positioning. This study examined the effect of the Infant Position Assessment Tool (IPAT) and informal education on the developmental positioning skills of NICU nurses. This quasi-experimental study measured IPAT scores before and after an educational intervention, and found a statistically significant increase in the means of the two groups. The use of the IPAT and bedside education is useful for improving the developmental positioning proficiency of NCU nurses.

Arlene Spilker

April 2015 



\title{
THE EFFECTIVENESS OF A STANDARDIZED POSITIONIONG TOOL AND BEDSIDE EDUCATION ON THE DEVELOPMENTAL POSITIONING PROFICIENCY OF NICU NURSES
}

by

Arlene Spilker

\author{
A thesis \\ submitted in partial \\ fulfillment of the requirements for the degree of \\ Doctorate of Nursing Practice \\ in the School of Nursing of Fresno State University \\ California State University, Fresno
}

May 2015 
For the Department of the School of Nursing:

We, the undersigned, certify that the thesis of the following student meets

and the studed standards of scholarship, format, and style of the university

degree.

\section{Arlene Spilker}

Thesis Author
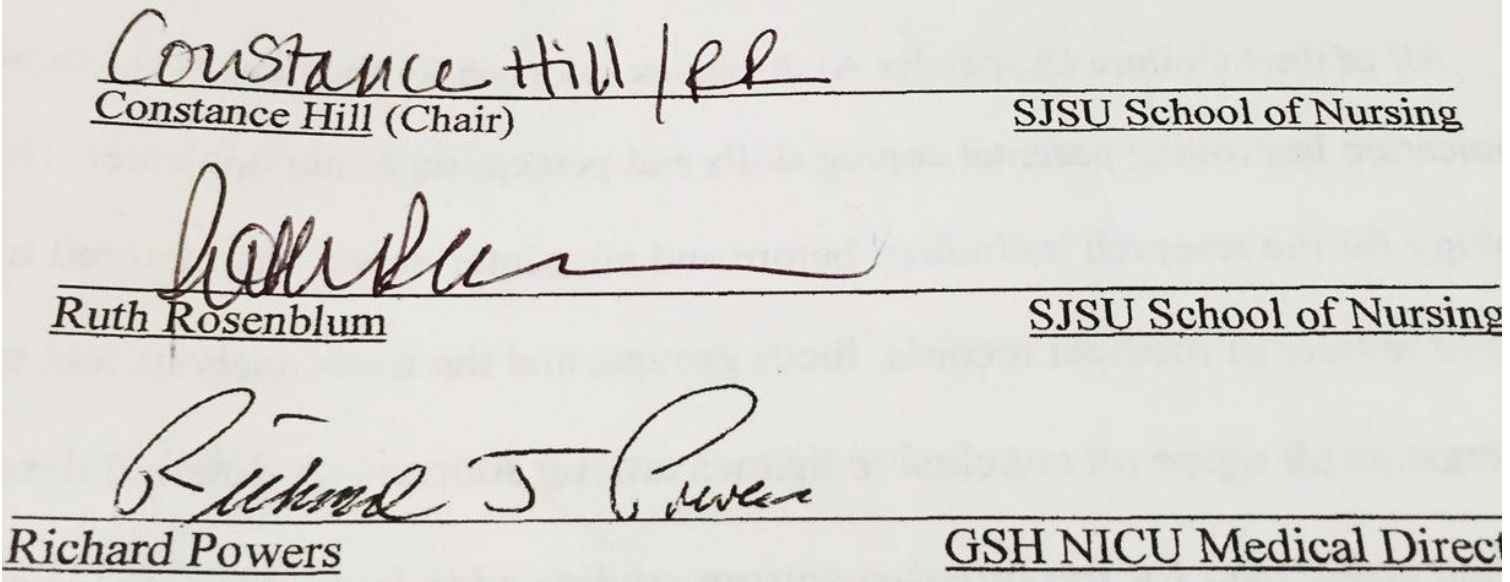

For the University Graduate Committee: 


\section{APPROVED \\ For the Department of the School of Nursing:}

We, the undersigned, certify that the thesis of the following student meets the required standards of scholarship, format, and style of the university and the student's graduate degree program for the awarding of the master's degree.

Arlene Spilker

Thesis Author

Constance Hill (Chair)

$\underline{\text { SJSU School of Nursing }}$

$\underline{\text { Ruth Rosenblum }}$

$\underline{\text { SJSU School of Nursing }}$

$\underline{\text { Richard Powers }}$

$\underline{\text { GSH NICU Medical Director }}$

For the University Graduate Committee:

Dean, Division of Graduate Studies 



\section{AUTHORIZATION FOR REPRODUCTION}

\section{OF MASTER'S THESIS}

X I grant permission for the reproduction of this thesis in part or in its entirety without further authorization from me, on the condition that the person or agency requesting reproduction absorbs the cost and provides proper acknowledgment of authorship.

Permission to reproduce this thesis in part or in its entirety must be obtained from me.

Signature of thesis author: Q Cuevergatke 


\section{ACKNOWLEDGMENTS}

Thank you to all of the members of my committee for their guidance; it has been truly appreciated. I also am indebted to the faculty of the California State University NorCal Consortium Doctorate of Nursing Practice program; they have been excellent instructors, mentors, and advisors, and I would not have been able to complete this project without their direction. I would also like to thank the staff at Good Samaritan Hospital Neonatal Intensive Care Unit in San Jose, California for their willingness to participate in this research. Special thanks go to the members of the developmental positioning team who assisted me with this research: Katie Church, Diane Crothers, Jennifer McDonald, Kat Quaile, Jill Pfeiffer, Kelly Ryan, Helene Rabajante, and Nicole Rohde. I would like to extend thanks to my two research assistants, Amanda Robinson and Radhika Kannan for collecting and entering the data, and my statistician Sulekha Anand for her expertise with the data analysis and interpretation. This project would not have been possible without the support of my husband David, and my children Sierra, Savannah and Jackson, and I share this achievement with them. 


\section{TABLE OF CONTENTS}

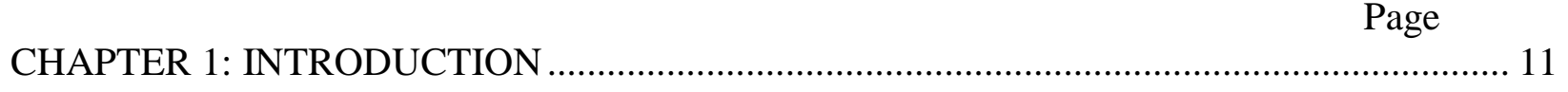

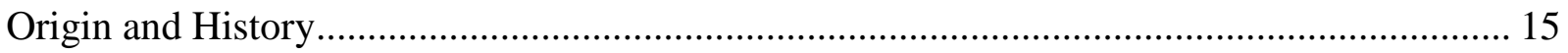

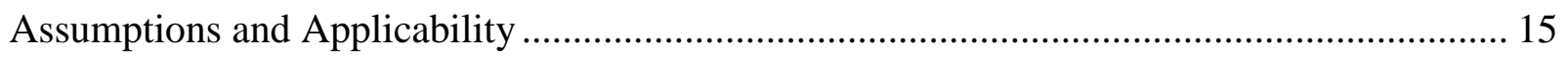

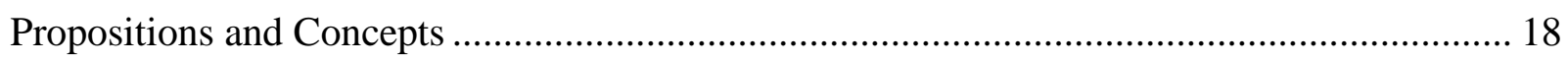

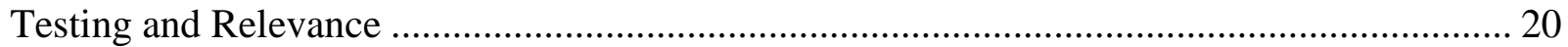

CHAPTER 2: LITERATURE REVIEW AND CRITIQUE ............................................... 21

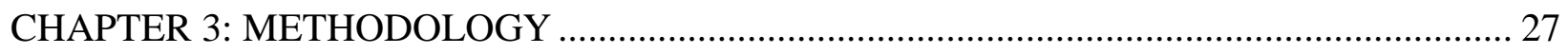

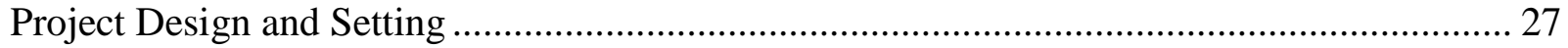

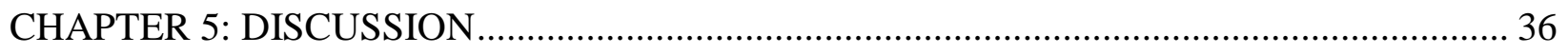

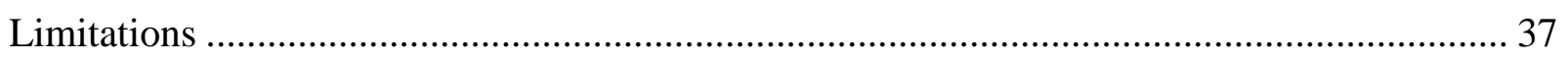

Implications for Nursing Practice and Conclusion ......................................................... 37

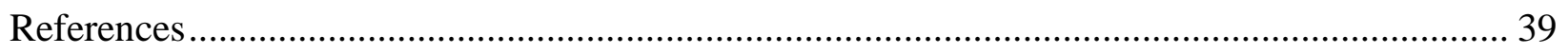

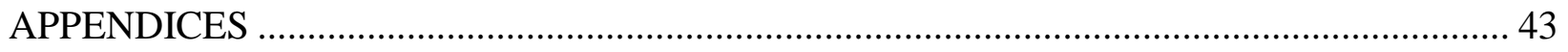

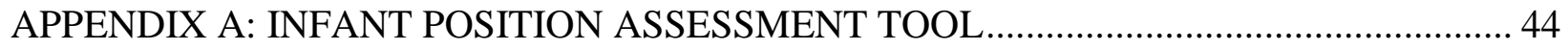

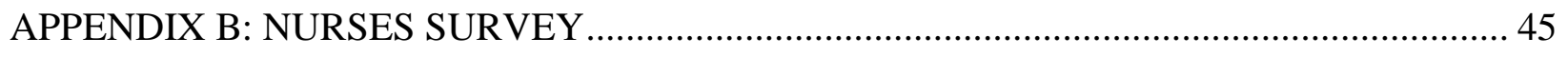

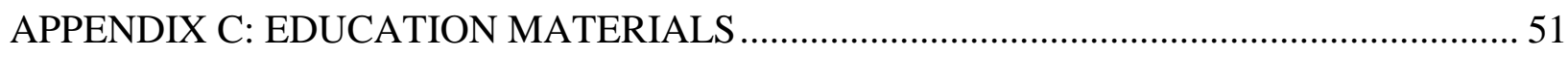

APPENDIX D: INTER-RATER RELIABILITY STATISTICS _...................................... 71

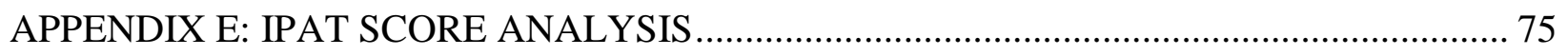

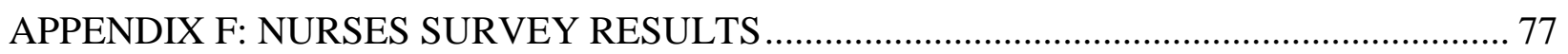




\section{CHAPTER 1: INTRODUCTION}

Preterm infants are a particularly vulnerable population who require technologically advanced medical interventions, and highly specialized nursing care in order to survive and thrive. Although many interventions have been aimed at decreasing the incidence of preterm births, the rate of preterm birth over the last 25 years has been relatively constant at approximately twelve percent of the births in the U.S. (Federal Interagency Forum on Child and Family Statistics, 2013). In the United States, preterm birth impacts about 500,000 infants every year, is the leading cause of long-term neurodevelopmental disability, and has an estimated cost of \$26 billion dollars per year ("Preterm Birth," n.d.). This problem is not limited to the United States; the World Health Organization estimates that preterm birth affects somewhere between five percent and eighteen percent of the infants born in 184 countries, or about 15 million preterm births every year ("Preterm Birth: Fact Sheet Number 363," 2013).

Infants born at less than 37 weeks gestation are considered preterm. This premature birth interrupts their intrauterine growth and development, and exposes them to an environment that is completely different from the womb, and their immature organs are not prepared for the "normal" newborn care environment of swaddling, breastfeeding, and being held by their family for hours at a time (Symington \& Pinelli, 2006). Extremely preterm ( $<28$ weeks) and moderately preterm (28-32 weeks) infants frequently require complex and highly technical interventions for survival, and their caregivers must have advanced knowledge and skills to ensure these infants survive even though they may be at the edge of viability (Louw \& Maree, 2005). Premature infants are an especially vulnerable population due to multiple factors (genetic endowment, physical environment, social environment, chronic stress, and health care) outlined in the conceptual model by Grumbach, Bravemen, Adler and Bindman (2007). 
Genetic endowment is the "gift" of being born with either a protection against, or a vulnerability towards, certain conditions (Grumbach, Braveman, Adler, \& Bindman, 2007). It is the most significant factor that makes preterm infants a vulnerable population Their early birth interrupts the maturity of their lungs, gut, brain, and immune system; this lack of development interferes with the most basic function of airway control and breathing, impacts digestive ability, jeopardizes brain function, and impairs immune function. The severity of these problems is inversely proportional to their gestational age, and the lower their gestational age, the higher their risk for morbidity and mortality. When preterm infants are born they are met with an assault of hands and tubes and procedures that (hopefully) ensures their survival. All of these lifesaving procedures also place the infant at risk for barotrauma, infection, fluid and electrolyte imbalances, and many other potential complications. In addition, their lack of self-regulatory behaviors, inability to make purposeful movements, and lack of communication abilities leave them extremely vulnerable.

For most preterm infants, instead of the physical environment of the warm skin of their mother's chest after birth, they are taken immediately to a pre-warmed bed, and interventions to initiate breathing are performed. The most invasive of these interventions include placement of an endotracheal tube, administration of artificial surfactant, initiation of assisted ventilation, and placement of arterial and venous umbilical catheters. The NICU is a bright, noisy, and busy environment, preterm infants rarely receive touch that would be considered "positive", and the majority of their interactions with other humans is of a professional rather than personal nature (Gibbins, Coughlin, \& Hoath, 2010; Louw \& Maree, 2005). Premature infants are regularly assessed and turned, but they are not swaddled because of the need for maximum observation. Additionally, the various tubes that are routinely placed in their trachea, esophagus, arteries and 
veins can impact their comfort and ability to be positioned in a developmentally appropriate manner (VandenBerg, 2007). That environment coupled with the infants' inability to selfsoothe, poor cerebral blood flow regulation, and leads to infants whose sleep states are constantly interrupted, and whose allostatic load is most likely very high.

Infants have zero "social capital" (King et al., 2007, p. 7) other than their engaging appearance and their potential to live out their parents' unrealized dreams. They are powerless to survive without a significant contribution from at least one other individual, and a significantly larger group contribution is needed in order to thrive. In addition, the socioeconomic and education level of their parents greatly contributes to their outcomes once they are released from the hospital, and despite best intentions, their home environment may not provide the needed follow up care to ensure proper development

Access to care impacts some of these infants, and even with the best prenatal care, premature births are not completely preventable at this point; until there is a "cure" for premature birth, access to the appropriate level of care for these infants is imperative. Depending on the infant's gestational age and prenatal circumstances, delivery of the preterm infant should take place at a hospital with a NICU that can provide a higher level of care (ventilation, highly trained nursing staff, round the clock neonatology coverage, pediatric surgery services, etc.).

Although this population is quite vulnerable, they are also one of the most cherished populations in health care. Every parent wants a healthy, full term newborn, and most are willing to sacrifice a great deal in order to ensure the best possible outcome.

\section{Problem Statement and Theoretical Framework}

The tremendous physical, emotional, and economic implications of prematurity (and the associated potential long-term negative effects) make it a significant worldwide problem ("Fact 
Sheet Number 363," 2013). Additionally, the lack of significant progress in the prevention of preterm births leads one to believe that more focus should be aimed at decreasing the negative sequelae of preterm birth. Thus, more research is needed on maximizing the proper growth and development of premature infants, particularly in the area of improving neurodevelopmental outcomes ((Louw \& Maree, 2005; VandenBerg, 2007)

Developmental care interventions have been shown to positively impact the neurologic outcomes and growth and development of preterm infants, and best practices for developmental care have been established, however they are inconsistently implemented (Gibbins et al., 2010). One aspect of developmental care has been found to be especially beneficial - developmental positioning, and although developmental positioning is recognized as an essential element of care in the Neonatal Intensive Care Unit (NICU), the definition and standardization of developmental positioning has not been fully researched or implemented into practice (Coughlin, Lohman, \& Gibbins, 2010). This project aims to improve the quality and consistency of the developmental positioning practices of the NICU at this facility by implementing a standardized developmental positioning resource and providing educational resources and bedside training. A secondary aim is to add to the body of knowledge about developmental positioning by adding evidence to support the use of a standardized positioning assessment tool as an education and evaluation resource.

The conceptual framework for this project is the theory of health promotion for preterm infants, which is a middle range theory based on Levine's conservation model of nursing; it originated as a dissertation (Mefford, 1999) followed by publication (Mefford, 2004) and testing of the theory (Mefford \& Alligood, 2011). Levine's conservation model of nursing theory emphasizes the concept of wholeness of the patient and interventions are aimed at conservation 
in four areas: energy, structural integrity, personal integrity, and social integrity. The theory assumes that the preterm infant is competent to survive in the intrauterine environment, but is not fully competent to survive in the extrauterine environment, and this poor fit results in four threats to the infant's wholeness: a threat to energy balance, a threat to structural integrity, a threat to personal integrity, and a threat to social integrity. These threats to the infants' wholeness are believed to impact short-term and long-term outcomes such as vital signs, pain scores, oxygen needs, weight gain, neurological development and musculoskeletal development (Mefford, 2004). The environmental challenges that these infants face impact their wholeness, and during their adaptation to extrauterine life, these threats should be minimized by implementing appropriate nursing interventions aimed at conserving and promoting wholeness (Mefford, 2004).

\section{Origin and History}

This model has been criticized due to the emphasis on the dependent nature of the patient (Levine's, n.d.) but I believe that makes it an "ideal conceptual framework" for the neonatal intensive care unit (Mefford, 2004, p. 260). Mefford used Fawcett's conceptual-theoreticalempirical structure along with linkages from a nursing conceptual model to develop a middle range theory that could be empirically tested; although this study was preliminary and the testing process in not complete, the theory of health promotion for preterm infants was supported and showed promise for improving nursing practice in the neonatal intensive care unit (Mefford, 2011).

\section{Assumptions and Applicability}

The theory assumes that the early delivery of the preterm infant disrupts their wholeness, with wholeness being defined as "the state when the internal environment and the external 
environment have the best fit or exist in a smooth interface" (Mefford, 2004, p. 260). The theory assumes that the preterm infant is competent to survive in the intrauterine environment, but is not fully competent to survive in the extrauterine environment, and this poor fit results in four threats to the infant's wholeness: a threat to energy balance, a threat to structural integrity, a threat to personal integrity, and a threat to social integrity. These threats to the infants' wholeness are believed to impact short term and long term outcomes such as vital signs, pain scores, oxygen needs, weight gain, neurological development and musculoskeletal development etc (Mefford, 2004). The environmental challenges that these infants face can impact their wholeness, and during their adaptation to extrauterine life, these threats should be minimized by implementing appropriate nursing interventions aimed at conserving and promoting wholeness (Mefford, 2004).

The theory assumes that the threat to energy balance is due to the physiologic immaturity of the infants, and this immaturity means that they expend a tremendous amount of energy keeping themselves warm, breathing, eating, and growing; that is, if they are able to do those things at all. Extremely preterm infants (28 weeks gestation) usually cannot perform any of those functions without multiple medical interventions (ventilation, intravenous fluids, medications, surgeries) and highly specialized nursing care. These life-sustaining interventions are frequently needed for several months, until the infants are physiologically mature enough to survive on their own; until that time, nursing interventions should be aimed at reducing energy expenditure and conserving energy in an effort to maximize growth and development.

The threat to structural integrity is also due to physiologic (as well as structural) immaturity. The systems of preterm infants do not function well because the organs/structures are neither mature nor fully formed; the lungs, gut, brain, and eyes are particularly vulnerable in 
a preterm infant, and many of the life-saving therapies (ventilation, oxygen, central lines) can damage these sensitive organs, sometimes irreversibly. Brain growth, muscle, fat development, and organ maturity are all interrupted by preterm birth, and preterm infants are at increased risk for intraventricular hemorrhage, periventricular leukomalacia, retinopathy of prematurity, chronic lung disease, musculoskeletal deformities, and other organ damage (Legendre, 2011). These conditions are potentially devastating, life-long conditions that tremendously impact the quality of life for these infants and their families. These negative sequelae are directly impacted by the nursing care that the infant receives, and interventions should be aimed at conserving structural integrity and minimizing structural injury (Mefford \& Alligood, 2011).

The threat to personal integrity is caused by the immaturity and fragility of the preterm infant's central nervous system. Personal integrity consists of having feelings of self-identity, self-concept, and self-worth, and although infants do not have the cognitive ability to communicate these feelings, the neurologic foundation for personal integrity is being formed from the moment the baby is born (Mefford, 2004). Developmental positioning and handling can decrease the stress response, prevent intraventricular hemorrhage, and provide the infant with experiences that promote neurodevelopmental competence. By properly responding to the infant's cues and anticipating their response to interventions, nurses can prevent added stress on the infant, and provide an environment where the infant can begin to develop trust. This conservation of personal integrity is in the direct control of the bedside nurse, and implementing developmental positioning and handling can positively impact neurodevelopmental outcomes (Mefford \& Alligood, 2011).

Finally, social integrity for the infant is determined by the structure and functioning of the family and a preterm birth poses multiple challenges for families (Mefford, 2004). The 
disruption of the family unit that occurs with the delivery of a preterm infant induces a great deal of stress on the family, and negatively impacts family functioning. Parents are grieving the loss of a healthy newborn, and must adapt to the care that is now required for their infants to survive and thrive. Parents are separated from their infants and are often unable to hold or feed their baby for weeks or months, and all of this occurs while they simultaneously relinquish much of their control to complete strangers, until their baby is mature enough for more routine newborn care. Providing support and education for families is an essential element of nursing care in the NICU, and implementing proper positioning and handling models appropriate care for the parent. Involving and educating parents also allows them to observe their infants comfortably positioned and sleeping peacefully, or reacting to handling without crying or decompensating physiologically (apnea, bradycardia, desaturations). All of these elements contribute to conserving the social integrity of the infant and family, and some also believe that it improves the relationships between the nurse and parents, as well as the satisfaction of all parties.

\section{Propositions and Concepts}

The theory of health promotion for preterm infants based on Levine's conservation model of nursing proposes that modifying the external environment of the preterm infant allows for successful adaptation to extrauterine life, and will assist in conserving wholeness in the four areas of threat (Mefford, 2004). The theory also proposes that the nursing care that conserves wholeness will result in the outcomes of physiologic stability and growth, minimal structural injury, neurodevelopmental competence, and stability of the family system and integration of the infant into the family (Mefford, 2004).

Multiple nursing interventions aimed at conserving energy are recommended in this theory in an effort to minimize the threat to energy balance; many of these interventions directly 
align with the interventions in my proposed positioning and handling project. These interventions include properly positioning the infant and providing an environment that maintains the airway, promotes thermal regulation, and maximizes rest periods; interventions also include handling infants in a manner that keeps the infant calm, decreases oxygen needs, and minimizes pain. Developmental positioning and handling directly impacts the amount of energy the infant expends in several ways; infants who are properly positioned and handled cry less, have less flailing of extremities, and have fewer behavioral indicators of pain (Gibbins, Hoath, Coughlin, Gibbins, \& Franck, 2008).

Minimizing structural damage by implementing meticulous nursing care (vigilant infection control, promoting optimal ventilation, maintaining stable blood pressure, and providing developmental positioning) can prevent damage to multiple organ systems. Developmental positioning and handling prevents fluctuations in cerebral blood flow, and can prevent the fragile blood vessels in the brain from rupturing and causing intraventricular hemorrhage. Developmental positioning also facilitates ventilation and can help prevent trauma to the airways, both of which can aid in the prevention of chronic lung disease. Finally, positioning the infant with a midline orientation, and providing appropriate boundaries and support to promote physiologic flexion will be a major goal of this project, and these interventions directly influence the goal of minimizing musculoskeletal damage.

Preserving personal integrity can be facilitated by protecting the delicate central nervous system of the infants; this is accomplished by interpreting and responding to the infant's cues and by manipulating the environment to provide an optimal environment for growth and development. Responding to behavioral cues and providing slow, gentle handling that promotes flexion can decrease the stress level of the infants (and parents) as well as promote an 
atmosphere of trust for the infant. Minimizing pain and discomfort by properly handling and positioning will also decrease stress and promote positive neurological development (Legendre, 2011)

Finally, social integrity can be promoted by providing parental support and education, and facilitating the bond between the parents and the infant. The preterm infant leaves the NICU with a minimal set of skills and almost no coping mechanisms, and they are completely dependent upon their parents for survival and success. To conserve social integrity it is imperative that nursing does its best to prepare and support families for the challenges that are inherent during the birth and early life of preterm infants.

\section{Testing and Relevance}

In an effort to provide a guide for neonatal nursing practice, the theory of health promotion for preterm infants based on Levine's conservation model of nursing was developed and described in a dissertation (Mefford, 1999), this was followed by a publication (Mefford, 2004) and the theory was subsequently tested and supported for use as a theoretical framework for neonatal nursing (Mefford \& Alligood, 2011). This testing was preliminary and further testing is in process, but initial evaluation of the theory was positive, and further testing will hopefully continue to support that evaluation. The theory of health promotion for preterm infants is concise and practical, and it has a simplicity that makes it likely to be understood by most registered nurses. The concepts and definitions are clearly described, and the recommendations for practice are applicable and appropriate for this population. All of these characteristics make it the most appropriate theory for this project.

Multiple nursing interventions aimed at conserving wholeness are recommended in this theory, and these interventions directly align with the interventions in the proposed positioning 
project. Properly positioning the infant promotes normal postural and musculoskeletal development, maintains a patent airway, promotes thermal regulation, and maximizes rest periods; additionally, infants who are properly positioned cry less, have less flailing of their extremities, and fewer behavioral indicators of pain (Coughlin et al., 2009; Gibbins et al., 2008). The theory of health promotion for preterm infants is concise and practical, and it has a simplicity that makes it likely to be understood by most registered nurses. The concepts and definitions are clearly described, and the recommendations for practice are applicable and appropriate for this population. This theory aligns well with neonatal nursing practice, and its simplicity and brevity is appealing. The project is very hands on, concrete, and focused, and those elements are also prominent in the theory for health promotion for preterm infants. The theory also appeals to me because the four areas of focus are very similar to my own personal belief about excellent nursing care in the NICU. My practice over the years have led me to believe that the elements of: maximizing growth, protecting the brain, minimizing organ damage, and promoting family function, are the foundation for care; these are essentially the same focus areas described in the theory of health promotion for preterm infants.

\section{CHAPTER 2: LITERATURE REVIEW AND CRITIQUE}

Developmental care has been extensively studied and there is a significant amount of research available to practitioners; however, many of these studies reveal conflicting results and conclusions, and further research is generally recommended in most research articles (Milette, Richard, \& Martel, 2005; Ohlsson \& Jacobs, 2013; Symington \& Pinelli, 2006). Using the keywords "developmental care" and "NICU" a search of the CINAHL database yielded 70 citations: a search of the PubMed database using the same keywords yielded 1034 citations. These citations represented all levels of evidence, from opinion to Cochrane systematic reviews, 
and the methods and interventions were quite diverse. Developmental care interventions vary widely from simple to complex, and the outcomes of those interventions also vary. A general discussion of developmental care will be followed by a more specific discussion of the concept of developmental positioning.

Any review of the literature regarding developmental care will most likely include the Neonatal Individualized Developmental Care and Assessment Program (NIDCAP). The NIDCAP is the "most extensive, evidence-based model of developmental supportive care" ("NIDCAP Mission," n.d., para. 1) and the NIDCAP certification process is a highly specialized set of assessments, training sessions, and interventions. The NIDCAP certification process requires a substantial financial investment from the hospital, along with a significant change in unit culture and nursing practice; this extensive commitment hinders its feasibility, and it may not be possible for some organizations to implement this widespread a developmental care program. Additionally, research findings regarding the effectiveness of the NIDCAP intervention are mixed; for example, the Cochrane collaboration found conflicting results in the multiple meta-analyses they reviewed (Symington \& Pinelli, 2006), and one of the most recent metaanalyses and systematic reviews concluded that NIDCAP did not improve long-term neurodevelopmental outcomes or short-term medical outcomes (Ohlsson \& Jacobs, 2013).

The complexity and variety of developmental care interventions make it especially difficult to determine which intervention affects which outcome. The challenges of determining the impact of developmental care is well stated in the Cochrane review:

Because of the inclusion of multiple interventions in most studies, the determination of the effect of any single intervention is difficult. Although there is evidence of limited benefit of developmental care interventions overall, and no major 
harmful effects reported, there were a large number of outcomes for which no or conflicting effects were demonstrated. ... before a clear direction for practice can be supported, evidence demonstrating more consistent effects of developmental care interventions on important short- and long-term clinical outcomes is needed. The economic impact of the implementation and maintenance of developmental care practices should be considered by individual institutions (Symington \& Pinelli, 2006, p. 2).

Although the Cochrane collaboration concluded that the benefit of developmental care is limited, there is significant evidence that at least one element of developmental care developmental positioning - has consistently been found to improve outcomes in several areas (Coughlin et al., 2010; Madlinger-Lewis et al., 2014; Picheansathian, Woragidpoonpol, \& Baosoung, 2009).

Developmental positioning (often called developmentally supportive positioning) is an intervention that has been proven to improve postural and musculoskeletal outcomes (Coughlin et al., 2010; Hunter, 2011; Jeanson, 2013; Madlinger-Lewis et al., 2014; Zarem et al., 2013), as well as improve physiologic outcomes and sleep states (Picheansathian, Woragidpoonpol, \& Baosoung, 2009). However, developmental positioning is not a standardized intervention, and various methods of providing developmental positioning have been studied; these methods include the use of commercially available products such as the Snuggle-Up and Bendy Bumper (Philips), the Dandle Roo (Dandle Lion Medical), and the Sleep Sack (HALO), as well as the use of simple linen rolls to provide boundaries and supports or "nesting" materials for the infant (Coughlin et al., 2010; Hunter, 2004/2011; Jeanson, 2013; Madlinger-Lewis et al., 2014).

The research is clear that developmental positioning is "acknowledged as a key element of care in the NICU", but there is "inconsistent adoption and implementation of developmental 
positioning world-wide" (Coughlin et al., 2010, p. 104). Additionally, a false sense of security can occur when NICUs use positioning aids and can verbalize keywords such as "midline" and “containment" (Hunter, 2011, p. 2). There is a disconnect between what is known in the evidence and what is practiced in some NICUs; although it is clear that developmental positioning is effective in improving outcomes, less is known about how to improve the developmental positioning proficiency of the nurses providing the care.

A literature search of CINAHL and PubMed using the keywords "developmental positioning" and "NICU" yielded 41 citations; the majority was focused on the outcomes of developmental positioning, or included developmental positioning as one element of a larger developmental care program. However, five articles, whose specific aims were to improve the developmental positioning of registered nurses in the NICU, were found.

In 2005, Louw and Maree developed a positioning and handling scale, and exposed the NICU nurses to developmental care principles via an educational workshop. The study had a small sample size $(n=11)$, and reliability of the tool was not established, but findings indicated that improvement in developmental positioning and handling competencies was obtained after a formal exposure to developmental principles (Louw \& Maree, 2005). In 2009, Giometti, Baroni, Artese, and Davidson surveyed Italian nurses in three NICUs to determine the educational needs surrounding developmental positioning (they used the term "postural care"). They had a response rate of $81.2 \%$, and the nurses identified two obstacles to providing postural care - lack of supplies, and lack of knowledge (Giometti, Baroni, Artese, \& Davidson, 2009). This article is only published in Italian, so further information is not available. In 2014, a team in Taiwan developed a positioning assessment tool, and provided audiovisual education to improve 
positioning outcomes; this particular article is in Chinese, so details regarding the research was limited to what was found in the abstract (Chen, Lin, Su, Lin, \& Hsu, 2014).

Jeanson (2013) used bedside nurse education and a standardized Infant Positioning Assessment Tool (IPAT) to improve positioning consistency. The IPAT (see Appendix A) was developed between 2007 and 2010 by Coughlin, Lohman, and Gibbins (2010) and Children's Medical Ventures (part of the Philips Corporation). Children's Medical Ventures manufactures developmental positioning products such as gel pillows for postural support, and boundaries for containment, and they have copyrighted the IPAT. The researchers developed the tool with three goals for use: as a reference and educational tool for teaching, as an evaluation instrument, and as a method of standardization. Coughlin et al. (2010) established content validity of the tool using research evidence and the opinions of clinical experts and developmental care researchers. Reliability was established by having multiple independent reviewers compute scores for five infants, and then evaluating them for consistency. The researchers (along with Children's Medical Ventures) then implemented an educational program at six different NICUs. These six hospitals all had statistically significant increases in their IPAT scores after the intervention.

Jeanson (2013) used the IPAT and one-to-one bedside education with the staff at a 52bed level IIIb NICU in the Midwest. This unit had multiple exposures to positioning education in several formats (skills lab, article review, bedside electronic reference sheets, etc.) over the years, but developmental positioning was still inconsistent (Jeanson, 2013). Jeanson surveyed the nursing staff to "determine their perceived comfort with positioning protocols" (Jeanson, 2013, p. 28) and recruited a team of nurses, nurse practitioners (NPs) and physical therapists (PTs). These nurses, NPs and PTs became the IPAT team who rated the infants' positioning and provided the bedside education. The author does not indicate how many members were on the 
IPAT team, and inter-reliability was reported at $98 \%$, but no indication was given as to what statistical test determined that number (Jeanson, 2013). This research was conducted in three phases.

After establishing reliability, phase one consisted of IPAT score collection on all infants younger than 34 weeks gestation by a four to five person IPAT team. One month after baseline was established, phase two began; it consisted of scripted education paired with IPAT evaluation of all infants (less than 34 weeks gestation) over a period of two months. Nurses who received scores of nine or greater on the IPAT received positive feedback, and those with a score of eight or less were provided scripted education (Jeanson, 2013). Phase three took place four months after the initial bedside education, and consisted of collection of IPAT scores by reliable team members.

Pre, intra, and post-intervention IPAT scores were analyzed using a modified $t$ test and indicated that in the three phases, mean IPAT scores were 8.3, 8.7, and 9.2 respectively; the change in scores was not statistically significant (Jeanson, 2013). The NICU staff survey had a $44 \%$ response rate, and of those who responded " $98 \%$ indicated that they were competent at positioning according to the protocol” (Jeanson, 2013, p. 28). Other findings from this study indicated that there were differences between staff perceptions and actual positioning practices, that the IPAT was an effective tool for assessing positioning (as well as being sensitive to change over time), and that head, neck and hand positioning were the most "problematic aspects of positioning” (Jeanson, 2013, p. 29).

Limitations for this study included small sample size (31, 21, and 37 infants), and variables such as staff scheduling patterns and census fluctuations; also there was no opportunity to retest all of the nurses after the intervention, and pair their results to obtain more information 
(Jeanson, 2013). Although the results of the study were not statistically significant, there were some valuable lessons learned. First, nurse to nurse education was the best way to get "buy in" from the bedside nursing staff, second, randomly assessing the performance inspired improved positioning, and third, feedback with hands on correction allowed the nurses to see the immediate benefits of developmental positioning (increased relaxation, decreased respiratory rate etc.) (Jeanson, 2013).

Clearly, there is a need to improve developmental positioning of NICU patients, and several researchers have developed standardized tools to assess positioning. The IPAT is an available tool that has been determined to be valid and reliable, but there have been limited published research studies (the literature searches revealed two articles - Coughlin et al., 2010 and Jeanson, 2013) that used the IPAT as part of the research, and the standardized definition of developmental positioning remains undetermined.

This project aims to improve the quality and consistency of the developmental positioning practices of the NICU at this facility by implementing a standardized developmental positioning resource (the IPAT) and providing educational resources and bedside training. Due to the strong evidence that indicates developmental positioning has several real and potential positive outcomes, and that no negative outcomes have been proven to be associated with developmental positioning, it is reasonable that a low risk intervention, using a tool that has been proven reliable and effective, should be implemented into practice.

\section{CHAPTER 3: METHODOLOGY}

\section{Project Design and Setting}

This quality improvement project was a quasi-experimental, pre-test post-test intervention implemented in a 46 bed, level III NICU at Good Samaritan Hospital, a facility 
which is owned by the for-profit Hospital Corporation of America (HCA). Good Samaritan Hospital is located in San Jose, CA and the NICU cares for infants with a wide variety of diagnoses, including prematurity, respiratory distress syndrome, congenital anomalies, and many others. The average daily census for the NICU during the research was approximately 35 patients. The education provided on developmental positioning has been scant. The only formal education was via a yearly skills lab approximately ten years ago, and new registered nurses receive articles about developmental care, but no other information or training.

The NICU generally has a wide variety of developmental positioning products available, but at the time of this research, the gel filled pillows (used for postural support of the infant) were not in stock. There were quality control and backorder issues with the gel products resulting in their not being available. Because this manufacturer was the only one who contracted with the hospital, no gel products from another vendor could be ordered without a lengthy process of negotiation and contract completion.

\section{Population and Sample}

A convenience sample from the registered nurses in the NICU was used for this research. There are approximately 100 registered nurses on the staff in the NICU, but at the time of the research, there were multiple fluctuations in staff numbers due to leaves of absences, the use of temporary staff (traveling nurses), the hiring of new nurses and nurses leaving their positions. During the time of the research the number of active nurses was approximately 80 .

\section{Interventions}

A team of eight nurses (and the primary researcher) was selected from the NICU staff to be members of the developmental positioning team. These nurses were from all three shifts, and had demonstrated both proficiency in developmental positioning, and an interest in improving 
the consistency of infant's positioning in the NICU. These team members collected IPAT scores pre and post intervention, helped spread the word about the research, and acted as resources to the staff in the NICU. The original plan was that the team would provide one-to-one bedside education to all of the registered nurses in the NICU (similar to the approach in Jeanson's research). However, due to time constraints and staffing factors, this was not possible and only 12 nurses were able to have this one-to-one education.

After determining inter-rater reliability (IRR), the developmental positioning team collected IPAT scores for infants in the NICU. Scores were collected on infants who were $<34$ weeks gestation, in incubators, and using developmental care supplies (Snuggle-Up, Bendy Bumper etc.). Swaddled infants and infants in open cribs were not scored. After these scores were obtained a survey (see Appendix B) was distributed to the NICU nurses and the intervention phase began. The survey consisted of demographic data and a few questions about developmental positioning knowledge and beliefs. The intervention consisted of introduction of the IPAT tool and several types of educational materials.

The primary researcher created educational materials in multiple formats (see Appendix C). These materials were individualized for this particular NICU, a busy unit with heavy nursing assignments, insufficient staffing on many shifts, and a temporary lack of commercially available developmental positioning products (specifically gel pillows that provide postural support). The educational materials were viewable in less than 30 minutes (from work or home) and emphasis was placed on providing postural support using linen and blanket rolls until the gel pillows become available again. The materials consisted of an IPAT at every bedside, a narrated slide presentation that was available on YouTube, hard copies of slides and information in each of the NICU open bay rooms, and the break room, and a set of slides on each of the bedside computers 
in the NICU. The limitations of the NICU bedside computers (no internet access and limited slide show presentation software) diminished the quality of that particular method of education, as it had no audio component, and it was not able to be viewed with presenter notes which contained the bulk of the information. The nurses anecdotally indicated that the YouTube and hard copy versions of the materials were more beneficial than those available on the NICU bedside computers.

During the month long intervention phase, the nurses were encouraged to take the survey, to review the materials (particularly the IPAT), and to use the developmental positioning team members as resources. Attempts were made by the team to educate the staff, but time constraints and staffing patterns prevented this from occurring, and it is unknown exactly how many staff members viewed any of the educational materials. After one month, 55 IPAT scores were collected on infants who were $<34$ weeks gestation, in incubators, and using developmental care supplies (Snuggle-Up, Bendy Bumper etc.). Swaddled infants and infants in open cribs were not scored.

\section{Instrumentation}

The IPAT tool and a brief survey developed by the primary researcher were used for this project. The IPAT has been found to be a reliable and valid tool as outlined in the literature review. The survey developed by the primary researcher contained demographic questions, and five open-ended questions regarding developmental care knowledge and beliefs.

\section{Data Collection}

The pre IPAT scores were collected over a period of 12 days, just prior to the beginning of the intervention. The post IPAT scores were collected over a period of eight days, just after the completion of the intervention. The NICU nurses survey was available to the NICU nurses 
during the entire month of the intervention. Surveys were available to the nurses in both paper and online versions.

\section{Data Analysis}

Inter-rater reliability (IRR) was obtained from the developmental positioning team by having each member independently determine IPAT scores for five "sample" infants, and then computing intraclass correlations for both consistency and absolute agreement. The preintervention and post-intervention IPAT scores were analyzed using a two-sample t-test because the group of nurses tested before the intervention was not the same group tested after the intervention. Levene's test was used to test for homogeneity of variances prior to the t-test. Demographic data and open-ended questions on the NICU nurses survey were collected for descriptive analysis.

\section{Ethical Considerations}

This research project was approved by the Institutional Review Boards (IRBs) of both Good Samaritan Hospital and Fresno State University. Both IRBs determined this study to be of minimal risk as the positioning practices were evidence-based and the population being measured is the registered nurse. An introductory letter outlining the participants' rights accompanied the NICU nurse survey. To prevent bias, the survey was voluntary and all data were aggregated before analysis by the primary researcher. The registered nurses were reminded throughout the study that the IPAT data being collected on their patients was for informational and educational purposes only. It was not being reported to administration, and there was no punitive aspect associated with achieving a low score on the IPAT. The IPAT measurements did not contain any identifiable information about the infant being scored, other than corrected gestational age, and a notation of any condition or equipment which may interfere with optimal 
developmental positioning. Again, all data were aggregated before analysis by the primary researcher. Additionally, registered nurses who were the caregivers at the time of scoring were not identified on the IPAT forms.

\section{CHAPTER 4: RESULTS}

Interrater reliability testing for the IPAT was completed for the nine raters: the IRR intraclass correlation for consistency of single measures was 0.797 and for consistency or average measures was 0.972 . The IRR intraclass correlation for absolute agreement of single measures was 0.712 and for absolute agreement of average measures was 0.957 . Cronbach's alpha was also calculated (0.972) and indicated that the IPAT had internal consistency (see Appendix D).

There were 54 pre-intervention scores and 55 post-intervention scores collected in two different samples of nurses. Levene's test indicated that the assumption of equal variances was met $(\mathrm{F}=1.546, \mathrm{p}=0.217)$ The independent samples $t$-test indicated a statistically significant $(t=$ -2.246, $d f 107$, sig $=0.027$ ) increase in the mean IPAT scores of the two groups. The mean IPAT score for the pre intervention group was 8.39 (standard deviation $=2.498)$ and the mean IPAT score of the post intervention group was 9.42 (standard deviation $=2.283$ ) (see Appendix E). 


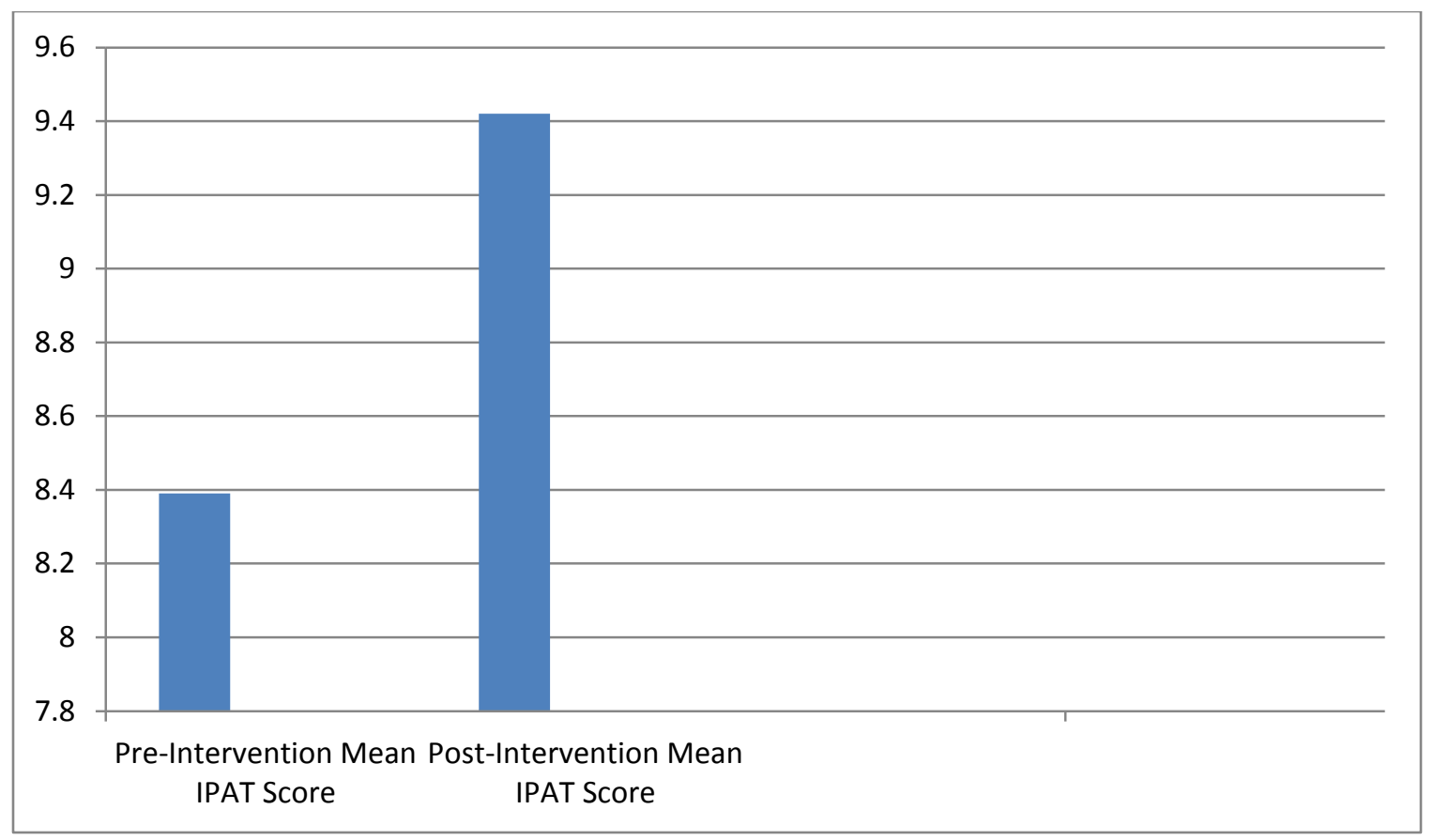

Figure 1. Mean IPAT Scores

The NICU nurses survey had a 50\% response rate $(n=41)$ (see Appendix F). The respondents were all female; they were primarily Caucasian (80\%) and Asian or Pacific Islander (13\%), and most were educated at a baccalaureate level or higher $(85 \%)$. They were primarily married or in a domestic partnership (76\%). Their ages varied widely as outlined in Table 1. Table 1. Nurses Ages

\begin{tabular}{lll}
\hline Range in Years & Number & Percentage \\
\hline $25-34$ & 10 & $24 \%$ \\
$35-44$ & 9 & $22 \%$ \\
$45-54$ & 15 & $37 \%$ \\
$55-64$ & 5 & $12 \%$ \\
$65-74$ & 2 & $5 \%$ \\
\hline
\end{tabular}


Table 2 describes the employment status of the respondents.

Table 2 Employment Status

\begin{tabular}{lll}
\hline Position & Number & Percentage \\
\hline 1.0 & 1 & $2 \%$ \\
0.9 & 3 & $7 \%$ \\
0.8 & 19 & $46 \%$ \\
0.7 & 1 & $2 \%$ \\
0.6 & 14 & $34 \%$ \\
0.5 & 2 & $5 \%$ \\
Traveler & 1 & $2 \%$ \\
\end{tabular}


Table 3 outlines the nurses years of practice in the NICU.

Table 3. Years of NICU Practice

\begin{tabular}{lll}
\hline Range in Years & Number & Percentage \\
\hline $1-4$ & 10 & $24 \%$ \\
$5-9$ & 6 & $15 \%$ \\
$10-14$ & 11 & $27 \%$ \\
$15-19$ & 6 & $15 \%$ \\
$20-24$ & 1 & $2 \%$ \\
$25-30$ & 3 & $7 \%$ \\
$31-35$ & 2 & $5 \%$ \\
$>35$ & 2 & $5 \%$ \\
\hline
\end{tabular}

When asked "How often do you use developmental positioning techniques in the NICU?" the respondents indicated that they "Always" (76\%) or "Usually" $(22 \%)$ used them, with one respondent (2\%) indicating they "Sometimes" used developmental positioning techniques. Responses to the open-ended query "Where/how/from whom did you learn about developmental positioning?" indicated that most nurses (42\%) learned from other registered nurses in the unit, and from the one skills lab mentioned previously (19\%). Others sources of developmental positioning education included conferences (12\%), books/articles $(12 \%)$, other hospitals (10\%), and sales representatives $(5 \%)$.

Responses to the prompt "Identify any barriers to implementing developmental positioning." indicated that the largest barriers were the lack of positioning supplies (32\%) and the lack of positioning education (27\%). Other barriers identified were patient factors such as 
medically necessary tubes and lines (24\%), nursing compliance (8\%), staffing issues and time constraints (6\%), and parental perceptions (3\%).

\section{CHAPTER 5: DISCUSSION}

Improving the developmental positioning proficiency of NICU nurses was a primary aim of this study. This aim is part of the larger goal of promoting positive outcomes for preterm infants. Preterm infants face four threats to their "wholeness" as described in the theory of health promotion for preterm infants (Mefford, 2004). These threats to energy balance, structural integrity, personal integrity and social integrity can be decreased with proper developmental positioning. Energy balance is positively impacted by providing secure boundaries and a womblike environment that promotes sleep. Structural integrity is maintained by preventing positioning associated deformities such as torticollis. Personal integrity is promoted when a wellpositioned infant sleeps for long periods of time and experiences minimal stress. Finally, social integrity is improved when parents are able to see their infants comfortably positioned and without evidence of stress. Developmental positioning can influence every aspect of the four threats to wholeness, and coordinates well with the theory of health promotion for preterm infants.

Results from this study indicate that the IPAT tool and informal access to education materials can be effective in improving the developmental positioning proficiency of NICU nurses. The mean IPAT scores improved after introducing the IPAT tool and making educational materials available to the registered nurses. Additionally, significant barriers to providing developmental positioning were identified: shortage of positioning supplies, lack of education, and patient factors. Some of these factors could possibly be eliminated as barriers, if the appropriate education and training were provided to the registered nurses. These findings are 
consistent with the limited evidence that was found in the literature review. The literature review and this research indicate that implementing a tool for standardizing positioning, and providing education to registered nurses can increase their developmental positioning proficiency. This study also adds evidence to support the use of the IPAT as an assessment and evaluation resource for developmental positioning.

\section{Limitations}

Limitations for this study include the short intervention time and the lack of availability of some developmental positioning supplies. The acuity of the infants may have differed preintervention and post-intervention which could have impacted the change in IPAT scores. Additionally, it is unknown how many nurses reviewed the provided educational materials, or if their attitudes or knowledge changed as a result of the intervention. This improvement in positioning may be temporary, and it is unknown if it will be sustained.

\section{Implications for Nursing Practice and Conclusion}

This study supports the use of a standardized positioning tool and bedside education as a strategy to improve developmental positioning proficiency. The information is directly applicable to practice, and a similar approach could be replicated at other facilities. This project did not require significant funding in order to achieve a change in practice, and it could be tailored to the individual needs of any NICU. The outcome also indicates that informal bedside education may be a viable alternative to formal education such as a skills lab; this may be useful in environments where education resources are limited.

Suggestions for future research include continued collection of IPAT scores for comparison. These measurements could take monthly or quarterly to assess if the change in positioning practices was sustained. Obtaining a post-intervention survey from the nurses would 
be beneficial to determine if there was a change in knowledge or attitudes, and to ascertain which intervention was most successful in changing their practice - was it the standardized tool, or was it the educational materials? Addressing the barriers identified by the nurses would be one of the next steps for this particular unit. Ideally, the NICU should obtain access to the gel pillows, and follow up education materials specifically geared toward removing the identified barriers should be developed. After the gel pillows are back in use, repeating this research project would be another area of interest.

Other potential research could focus on the effect of the IPAT on the infants long term outcomes such as musculoskeletal development, or the need for physical therapy. Replicating this study with the interdisciplinary team (specifically respiratory therapists, nurse practitioners, and physicians) is another area for study.

In conclusion, registered nurses require the appropriate tools and necessary education to provide patient care that is evidence-based and improves outcomes. This research indicates that implementing a simple tool and bedside education can be an effective and low cost strategy for facilitating practice change. Finally, the IPAT is a valid and reliable tool for improving developmental positioning practices of NICU nurses. 


\section{References}

Chen, C. M., Lin, K. H., Su, H. Y., Lin, M. H., \& Hsu, C. L. (2014). Improving the positioning and nesting for premature infants by nurses in neonatal intensive care units [Supplement]. Hu Li Za Zhi, 61. http://dx.doi.org/10.6224/JN.61.2.41

Coughlin, M., Gibbins, S., \& Hoath, S. (2009). Core measures for developmentally supportive care in neonatal intensive care units: Theory, precedence and practice. Journal of Advanced Nursing, 65(10), 2239-2248. http://dx.doi.org/10.1111/j.13652648.2009.05052.x

Coughlin, M., Lohman, M. B., \& Gibbins, S. (2010). Reliability and effectiveness of an infant positioning assessment tool to standardize developmentally supportive positioning practices in the neonatal intensive care unit. Newborn and Infant Nursing Reviews, 10(2), 104-106. http://dx.doi.org/http://dx.doi.org/10.1053/j.nainr.2010.03.003

Federal Interagency Forum on Child and Family Statistics. (2013). America's children: Key national indicators of well-being. Washington, DC: Government Printing Office.

Gibbins, S., Coughlin, M., \& Hoath, S. B. (2010). Quality indicators: Using the universe of developmental care model as an exemplar for change. In C. Kenner, \& J. McGrath (Eds.), Developmental care of newborns and infants: a guide for health professionals (2 ed., pp. 43-59). Retrieved from http://www.academia.edu

Gibbins, S., Hoath, S. B., Coughlin, M., Gibbins, A., \& Franck, L. (2008). The universe of developmental care: a new conceptual model for application in the neonatal intensive care unit. Foundations in Neonatal Care, 8, 141-147. 
Giometti, E., Baroni, L., Artese, C., \& Davidson, A. (2009). Postural care of newborns in the NICU: A study of nurses' educationl needs. Childrens's Nurses: Italian Journal of Pediatric Nursing Science, 1(3), 95-100.

Grumbach, K., Braveman, P., Adler, N., \& Bindman, A. B. (2007). Vulnerable populations and health disparities: An overview. In A. B. Bindman, \& K. Grumbach (Eds.), Medical management of vulnerable and underserved patients: Principles practice and populations (pp. 3-11). New York: McGraw-Hill.

Hunter, J. (2011). Therapeutic positioning; Neuromotor, physiologic, and sleep imiplications. Retrieved from Sundance Solutions.com (Reprinted from Developmental care of newborn infants; A guide for health professionals, by C. Kenner, \& J. McGrath, 2004)

Jeanson, E. (2013). One-to-one bedside nurse education as a means to improve positioning consistency. Newborn and Infant Nursing Reviews, 13(), 27-30. http://dx.doi.org/10.10553/j.nainr.2012.12.004

Legendre, V., Burtner, P. A., Martinez, K. L., \& Crowe, T. K. (2011). The evolving practice of developmental care in the neonatal unit: A systematic review. Physical and occupational therwpy in pediatrics, 31(3), 315-338. http://dx.doi.org/10.3109/01942638.2011.556697

Levine's four conservation principles. (n.d.). Retrieved September 2, 2013, from http://currentnursing.com/nursing_theory/Levin_four_conservation_principles.html Louw, R., \& Maree, C. (2005). The effect of formal exposure to developmental care principles on the implementation of developmental care positioning and handling of preterm infants by neonatal nurses. Health SA Gesondheid, 10(2), 24-32.

Madlinger-Lewis, L., Reynolds, L., Zarem, C., Crapnell, T., Inder, T., \& Pineda, R. (2014). The effects of alternative positioning on preterm infants in the neonatal intensive care unit: A 
randomized control trial. Research in Developmental Disabilities, 35, 490-497. http://dx.doi.org/10.1016jj.ridd.2013.11.019

Mefford, L. C. (1999). The relationship of nursing care to health outcomes of preterm infants: Testing a theory of health promotion for preterm infants based on Levine's conservation model of nursing (Doctoral dissertation). Available from ProQuest, UMI Dissertation Publishing. (UMI No.9944269)

Mefford, L. C. (2004, July). A theory of health promotion for preterm infants based on Levine's conservation model of nursing. Nursing Science Quarterly, 17(3), 260. http://dx.doi.org/10.1177/0894318404266327

Mefford, L. C., \& Alligood, M. R. (2011). Testing a theory of health promotion for preterm infants based on Levine's conservation model of nursing. The Journal of Theory Construction \& Testing, 15, 41-47. http://dx.doi.org/10.1177/0894318404266327

Milette, I. H., Richard, L., \& Martel, M. (2005). Evaluation of a developmental care training programme for neonatal nurses. Journal of Child Health Care, 9(2), 94-109. http://dx.doi.org/10.1177/1367493505051400

Ohlsson, A., \& Jacobs, S. E. (2013, February 18, 2013). NIDCAP: A systematic review and meta-analyses of randomized controlled trials. Pediatrics, 131, 881-893. http://dx.doi.org/10.1542/peds.2012-2121

Picheansathian, W., Woragidpoonpol, P., \& Baosoung, C. (2009). Positioning of preterm infants for optimal physiologic development: A systematic review. Joanna Brigss Institute Library of Systematic Reviews, 7(7), 224-259.

Preterm birth. (2013). Retrieved May 4, 2014, from http://www.who.int/mediacentre/factsheets/fs363/en/ 
Preterm birth. (n.d.). Retrieved May 1, 2014, from

http://www.cdc.gov/reproductivehealth/MaternalInfantHealth/PretermBirth.htm

Symington, A. J., \& Pinelli, J. (2006). Developmental care for promoting development and preventing morbidity in preterm infants. Cochrane Database of Systematic Reviews, (2). http://dx.doi.org/10.1002/14651858.CD001814.pub2.

The Mission of the NIDCAP Federation International. (n.d.). Retrieved May 3, 2014, from http://www.nidcap.org/about.aspx

VandenBerg, K. A. (2007). Individualized developmental care for high risk newborns in the NICU: A practice guideline. Early Human Development, 83(7), 443-442. http://dx.doi.org/10.1016/j.earlhumdev.2007.03.008

Zarem, C., Crapnell, T., Tiltges, L., Madlinger, L., Reynolds, L., Lukas, K., \& Pineda, R. (2013). Neonatal nurses' and therapists'perceptions of positioning for preterm infants in the neonatal intensive care unit. Neonatal Network, 32, 110-116.

http://dx.doi.org/10.1891/0730-0832.2.110 


\section{APPENDICES}


APPENDIX A: INFANT POSITION ASSESSMENT TOOL

\begin{tabular}{|l|l|}
\hline Patient's name: \\
\hline Clinician performing assessment: & \\
\hline Date/Time of Assessment: & \\
\hline Infant position (circle): Supine & Side-Lying $\quad$ Prone \\
\hline
\end{tabular}

\begin{tabular}{|c|c|c|c|c|}
\hline Indicator & $\mathbf{0}$ & 1 & 2 & Total score \\
\hline $\begin{array}{l}\text { - Shoulder } \\
\text { status }\end{array}$ & $\begin{array}{l}\text { Shoulders } \\
\text { hyperextended }\end{array}$ & $\begin{array}{l}\text { Shoulders flat/in } \\
\text { neutral }\end{array}$ & Shoulders softly rounded & \\
\hline $\begin{array}{l}\text { - Hand and } \\
\text { arm } \\
\text { location }\end{array}$ & $\begin{array}{l}\text { Hands away from } \\
\text { the body } \\
\text { Arms extended }\end{array}$ & $\begin{array}{l}\text { Hands touching } \\
\text { torso } \\
\text { Arms extended }\end{array}$ & $\begin{array}{l}\text { Hands touching face } \\
\text { Arms flexed }\end{array}$ & \\
\hline $\begin{array}{l}\text { - Pelvic } \\
\text { position }\end{array}$ & $\begin{array}{l}\text { Hips } \\
\text { abducted/externally } \\
\text { rotated, and/or in } \\
\text { extension }\end{array}$ & $\begin{array}{l}\text { Hips in alignment } \\
\text { but extended }\end{array}$ & $\begin{array}{l}\text { Hips softly flexed and in } \\
\text { alignment with pelvic tilt }\end{array}$ & \\
\hline $\begin{array}{l}\text { - Knees, } \\
\text { ankles/feet } \\
\text { orientation }\end{array}$ & $\begin{array}{l}\text { Knees extended, } \\
\text { ankles everted and } \\
\text { feet supinated }\end{array}$ & $\begin{array}{l}\text { Knees. ankles, feet } \\
\text { straight in } \\
\text { extension }\end{array}$ & $\begin{array}{l}\text { Knees, ankles and feet are } \\
\text { in midline orientation with } \\
\text { supported flexion }\end{array}$ & \\
\hline $\begin{array}{l}\text { - Head } \\
\text { position }\end{array}$ & $\begin{array}{l}\text { Head rotated } \\
\text { laterally }(\mathrm{L} \text { or } \mathrm{R}) \\
\text { greater than } 45^{\circ} \\
\text { from midline }\end{array}$ & $\begin{array}{l}\text { Head rotated } \\
\text { laterally }(\mathrm{L} \text { or } \mathrm{R}) \\
45^{\circ} \text { from midline }\end{array}$ & $\begin{array}{l}\text { Head positioned midline to } \\
\text { less than } 45^{\circ} \text { from midline } \\
\text { (L or R) }\end{array}$ & \\
\hline $\begin{array}{l}\text { - Chin/Neck } \\
\text { position }\end{array}$ & $\begin{array}{l}\text { Chin in deviated } \\
\text { laterally (L or R) } \\
\text { Neck in } \\
\text { hyperextension }\end{array}$ & $\begin{array}{l}\text { Chin in neutral } \\
\text { position without } \\
\text { tone }\end{array}$ & $\begin{array}{l}\text { Chin in neutral position } \\
\text { with tone } \\
\text { Neck aligned with spine }\end{array}$ & \\
\hline & & & Cumulative Score & \\
\hline
\end{tabular}

Please describe any special circumstances that restricted the infant's ability to be positioned in flexion, midline orientation, with containment:

Please describe any interventions/adjustments made to promote developmentally supportive positioning goals of flexion, midline orientation, with containment:

Ideal Score $=>9$ points 


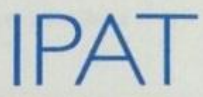

\title{
Infant Position Assessment Tool
}

\author{
Introduction \\ The Infant Position Assessment Tool (IPAT) is a six-item tool with cumulative \\ scores ranging from 0 to 12 . It was developed as a teaching tool to standardize \\ developmentally supportive positioning practices in the NICU and provides a \\ method for evaluation of those positioning practices. Content validity of the \\ IPAT is based on research evidence and opinions from both clinical experts and \\ researchers in developmental care.
}

How to use the tool (A, B, Cs)

A) The new user can review the various body part indicators and view least favorable to most favorable infant positions across each body part domain.

B) Once this baseline information is assimilated by the clinician s/he is ready to provide consistent developmentally supportive positioning. Using the tool as a reference, the clinician can position the infant optimally to promote musculoskeletal development, comfort and sleep

C) The tool is also used to assess the infant's position and repositioning needs prior to engaging in a caregiving interaction. Spontaneous movement is a natural phenomenon for infants; however, in the absence of therapeutic positioning supports, these spontaneous movements may leave the infant 'stranded' in a suboptimal position. Completing an IPAT with each caregiving exchange enables the developmentally supportive clinician to identify infant movements that may benefit from positioning supports as well as ensure that the infant is repositioned appropriately to promote comfort, sleep and musculoskeletal development.

\section{IPAT scores \\ An optimal IPAT score ranges between 10 to 12 points. There are several circumstances that may impede your ability to provide that degree of optimal positioning (e.g., infants with various venous or arterial access needs, drains, surgical sites, etc.), which is why it is so important to document the variance in your ability to provide optimal positioning for each infant. \\ In general, scores less than $\mathbf{8}$ indicate that the infant is in need of positioning support that offers containment, promotes flexion and ensures proper body alignment.}

\section{PHILIPS}

Children's Medical Ventures 


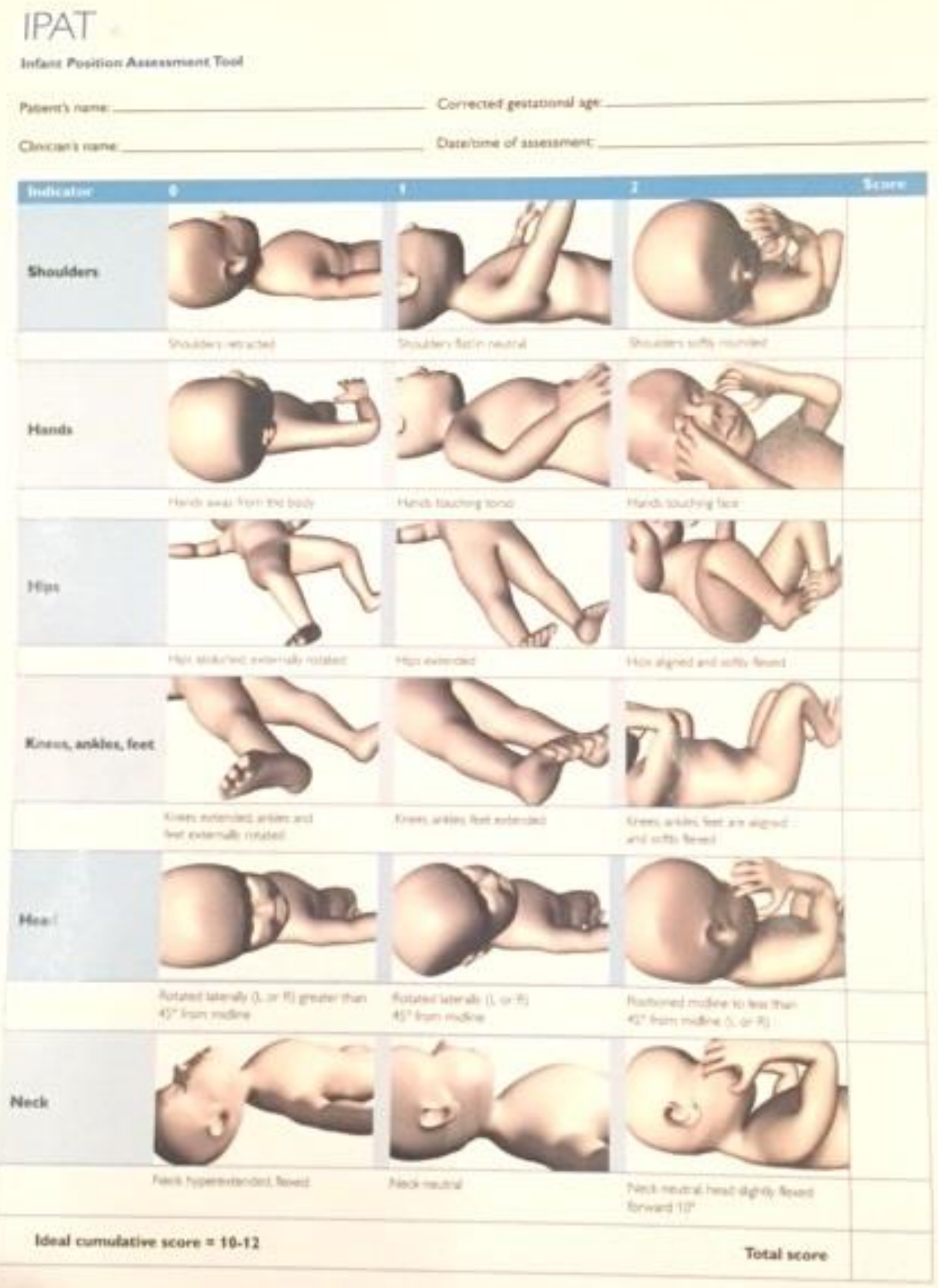




\section{APPENDIX B: NURSES SURVEY}

California State University, NorCal Consortium DNP Program

Department of Nursing-NorCal DNP

2345 San Ramon Avenue M/S MH 25

Fresno, CA 93740-8031

$559-278-2041$

Q1. Before you answer any survey questions, please read the following informed consent information.

I am conducting a study examining the developmental positioning practices of registered nurses in the NICU. This study will help fulfill the degree requirements for the Doctor of Nursing Practice degree at the California State University, NorCal Consortium, which is a joint venture between San Jose State University and Fresno State University. I am an employee in the NICU at Good Samaritan Hospital and I also work as a lecturer at San Jose State University.

This survey will take approximately 15 minutes to complete. Your identity will remain anonymous. No information you provide can be linked to you, and you should not identify yourself anywhere on the survey. Participation in the study is completely voluntary, and you may withdraw from the study at any time without consequence. You will not receive any compensation for participating in the study. By completing the survey, you are indicating that you understand this information and that you are willing to participate; a separate informed consent form is not required. There are no direct risks or benefits of participating in the study. Your contribution to this study will provide important information about how NICU nurses developmentally position their patients, and how to improve positioning practices.

Thank you for your participation in the survey. I have no conflict of interest to report and have received no funding for this project. I have received permission from Good Samaritan Hospital to conduct this study.

If you have any questions about your rights as a research participant, please contact me. 
Arlene Spilker DNPc, MS, RN

arlene.spilker@sjsu.edu

408-666-5444

Q2. What is your age?

○ 22-24 years old

○ 25-34 years old

○ 35-44 years old

○ 45-54 years old

○ 55-64 years old

○ 65-74 years old

○ 75 years or older

Q3. Please specify your ethnicity.

- White or Caucasian

- Hispanic or Latino

- Black or African American

- Native American or American Indian

- Asian or Pacific Islander

O Other - please specify

Q4. What is your highest level of education?

- Associate's Degree

- Bachelor's Degree

- Master's Degree

○ Doctoral Degree

Q5. What is your marital status?

- Single, never married

- Married or domestic partnership

○ Widowed

○ Divorced

- Separated

Q6. What is your employment status?

○ Status 1.0

○ Status 0.9

○ Status 0.8

○ Status 0.7

○ Status 0.6 
○ Status 0.5

- Per Diem

○ Traveler

Q7. How many years have you been a registered nurse?

○ 1-4 years

○ 5-9 years

○ 10-14 years

○ 15-19 years

○ 20-24 years

○ 25-29 years

○ 30-35 years

$\circ>35$ years

Q8. How many years have you worked in the NICU specialty?

○ 1-4 years

○ 5-9 years

○ 10-14 years

○ 15-19 years

○ 20-24 years

- 25-30 years

○ 31-35 years

○ >35 years

Q9. How often do you use developmental positioning techniques in the NICU?

- Never

○ Rarely

- Sometimes

- Usually

- Always

Q10. Which developmental positioning devices do you routinely use? Select all that apply.

- Gel Pillow/Squishon (rectangular)

- Gel - E Donut (circular)

- Gel Wedgie (triangular)

- Snuggle Up/Snugglie

- Bendy Bumper

○ Freddy Frog

- Linen Rolls (cloth diapers, blankets, t-shirts) 
Q11. Where/how/from whom did you learn about developmental positioning?

Q12. What is your definition of developmental positioning for preterm infants?

Q13. What are the risks of developmental positioning?

Q14. Identify any barriers to implementing developmental positioning?

Q15. What are the benefits of developmental positioning? 
APPENDIX C: EDUCATION MATERIALS

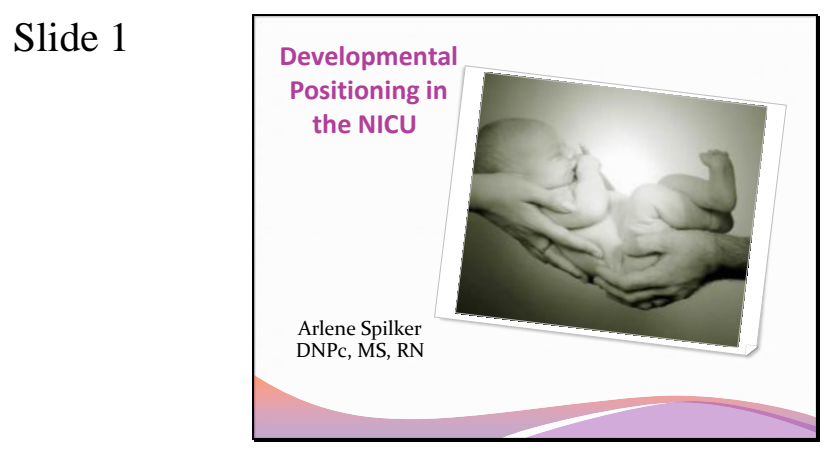

Hello, and thank you for taking the time to view this presentation! My name is Arlene Spilker. I am a staff nurse in the NICU at GSH, and I teach nursing school at SJSU. I am obtaining a doctorate in nursing practice, and my research project is aimed at improving developmental positioning for preterm infants. Developmental positioning has been a passion of mine during my 25 year practice, and I personally believe that it offers significant benefits for everyone involved - the infant, the RN, and the parents. Much of the evidence supports this belief, and I am hoping to positively influence the developmental positioning of the infants in our NICU with this education program, and perhaps add to the body of knowledge regarding developmental positioning. This presentation is one piece of this education program, and you will also see other education materials throughout the NICU. Additionally, a bedside consultation and teaching session with one of the members of the developmental positioning team will be available to you. 
Slide 2

Outcomes
- The participants will describe the
fundamental principles of developmental
positioning.
- The participants will discuss the current
evidence regarding the actual and potential
benefits of developmental positioning.
- The participants will identify fears or
concerns they have regarding developmental
positioning.

Slide 3

Slide 4

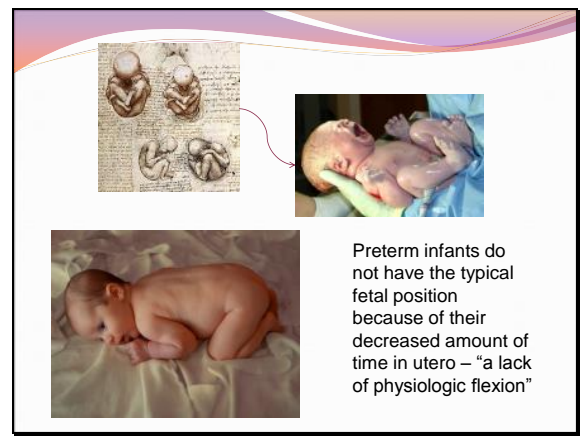

After completing the activities for this project (survey, bedside materials, slide presentation, bedside education session) you will be able to discuss the principles of developmental care, the current evidence regarding developmental care, and identify any concerns you have about developmental positioning.

You will also select or create the appropriate equipment for your patients, demonstrate optimal developmental positioning, and analyze barriers to developmental positioning.

Preterm babies do not have the same opportunity to build muscle and achieve flexion in utero, so we must provide them with those opportunities. 
Slide 5

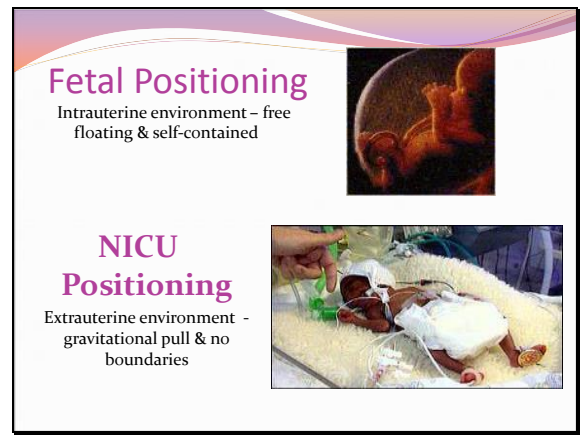

Slide 6

Why Are We NICU Nurses?

- To give babies the best possible start, no matter what their circumstances at birth may be.

- We enjoy the high-tech, high-touch environment.

- We like to incorporate the art and science of nursing

- We want the babies to become happy, healthy,

functioning members of society.

- Because we love babies.

- and many other reasons....

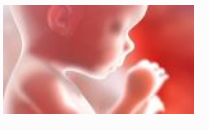

Slide 7

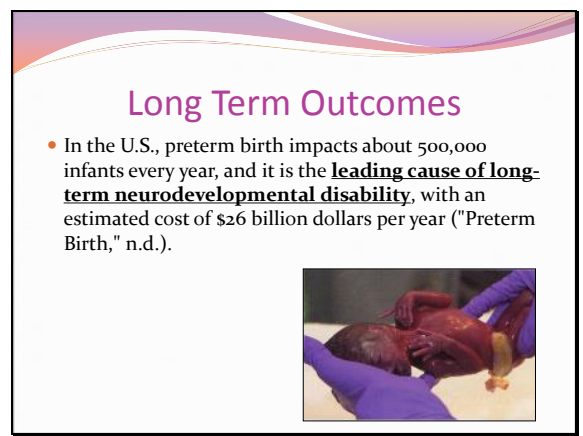

NICU nurses are notoriously protective of their patients, and have reputations as fierce patient advocates. The importance of the relationship between a NICU nurse and their patients cannot be overstated, and our ability to interpret very subtle cues makes the difference in the outcomes for that infant. We have more of an impact on their care than any other provider, and my hope is that after this research project is complete, you will understand the evidence regarding the benefits of developmental positioning and fully incorporate it into your daily practice.

We have made significant strides in keeping preterm infants alive, but we still have significant issues with negative outcomes, especially neurodevelopmental disabilities. Because our rate of preterm birth has remained relatively unchanged over the last 25 years, we need to focus on giving these babies the best start possible. One way we can do this is by providing developmental care. 
Slide 8

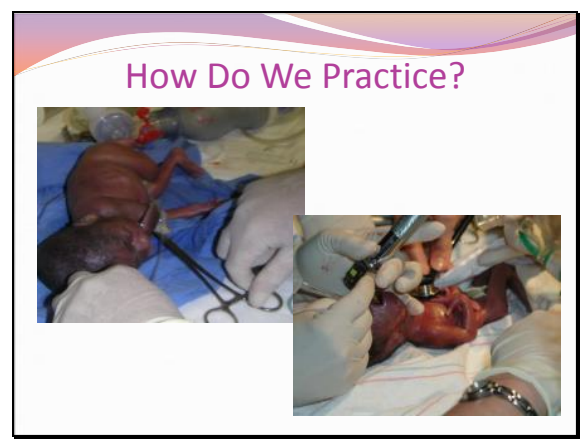

Slide 9

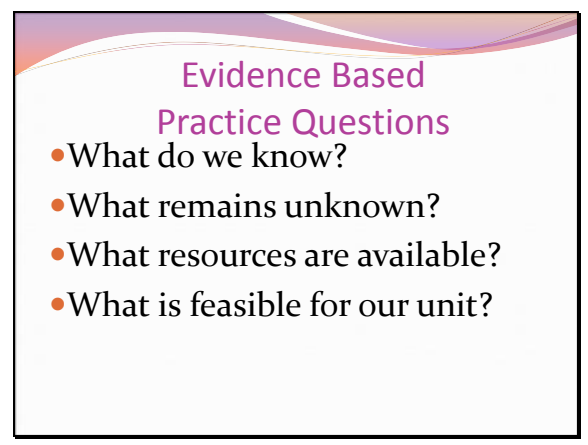

When we really look at our practice, we realize that we have a great opportunity to change. It is no longer enough to just save these babies lives, we must also support their proper development from the moment they are born. We have seen a very positive impact with our cue-based feeding protocol, and I am hopeful this project will have the same impact.

These are some of the questions that need to be answered with this kind of project. We know that the concept of developmental care has been studied extensively in the literature, and that no negative outcomes have been associated with developmental care. We also know that some elements of developmental care have been shown to be effective in improving outcomes, while other interventions do not have that evidence. We know that developmental positioning is one element of developmental care that definitely improves outcomes. We also need to consider what is reasonable for our facility and unit when implementing developmental positioning. 
Slide 10

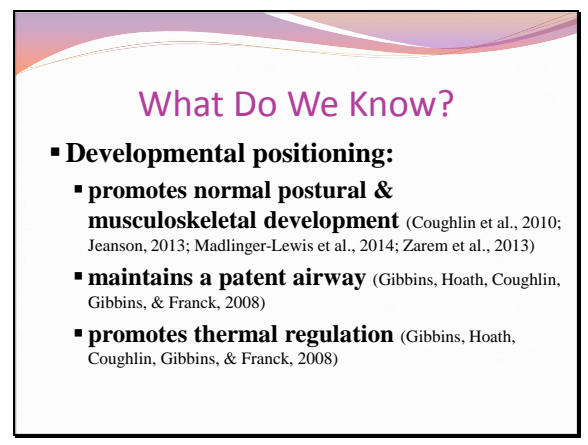

Slide 11

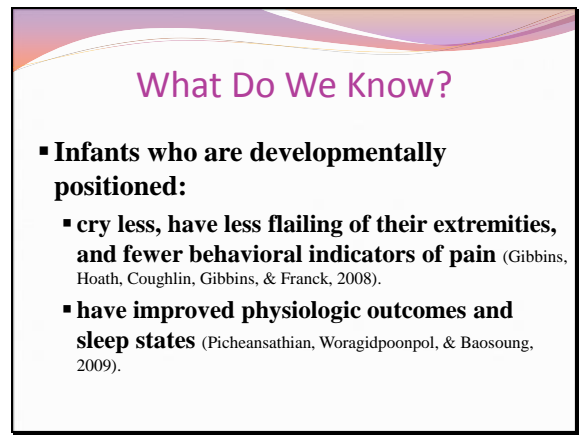

Slide 12

What Remains Unknown?

- The definition and standardization of developmental positioning has not been fully researched or implemented into practice (Coughlin, Lohman, \& Gibbins, 2010).

- Developmental positioning is inconsistently implemented (Gibbins. Coughlin, \& Hoath, 2010).
So, what do we know? We absolutely know that developmental positioning improves musculoskeletal development - multiple studies have proven it. However, we also know that it helps maintain a patent airway and improves thermal regulation.

Additionally, they sleep better, they cry and flail less, and they have decreased pain scores. There are multiple reasons to developmentally position the infant, and there is no evidence of any risks associated with developmental positioning. All of this has been shown in the literature, and many of our staff have also personally seen these same outcomes when they change their practice to fully implement developmental positioning.

The literature also states that developmental positioning is inconsistently applied, and that is true for our NICU as well. Most NICU nurses can verbalize the concepts and importance of developmental positioning, but they may not be proficient with their positioning skills, or they may have misconceptions or fears about developmental positioning. This project aims to assist with defining and standardizing the concept of developmental positioning. 
Slide 13

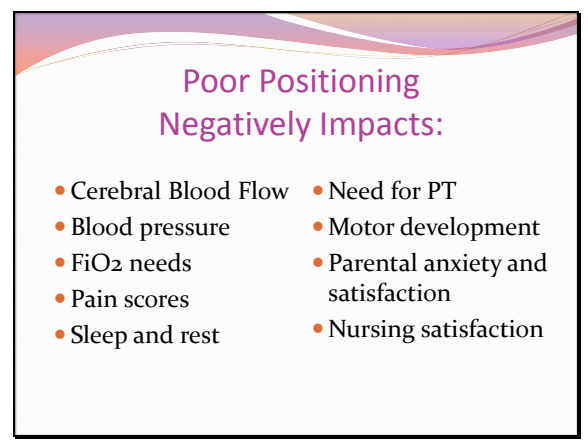

Slide 14

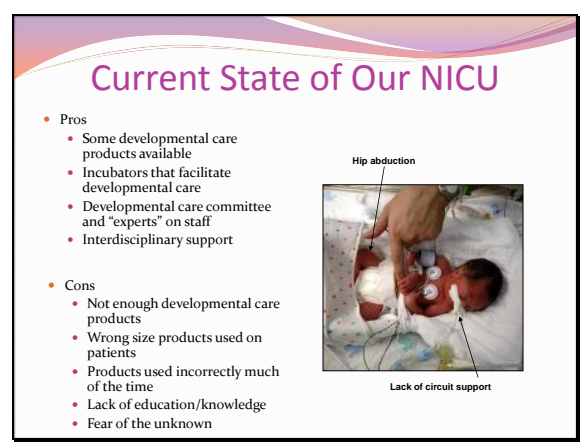

These are some of the effects of poor positioning that are being studied, as well as many others including longer lengths of stay, and developmental outcomes in infancy and childhood. We know it works, but it is difficult to get nurses to properly position for a variety of reasons.
As far as resources, recently, we have also not had access to the gel Squishons, which makes it more difficult to implement proper positioning, however, developmental positioning is less about the equipment and more about the positions we are trying to achieve. We can achieve those same positions with linen supports that are rolled or folded to the appropriate size.

We will also be implementing a standardized Infant Positioning Assessment Tool (the IPAT) to provide an education and evaluation resource. Be on the lookout for this resource on 
the unit.

Slide 15

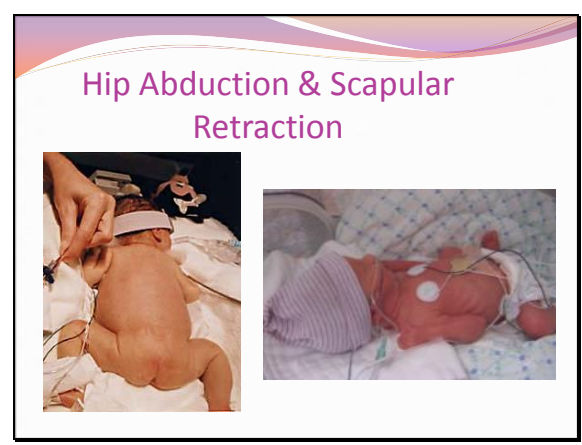

Slide 16

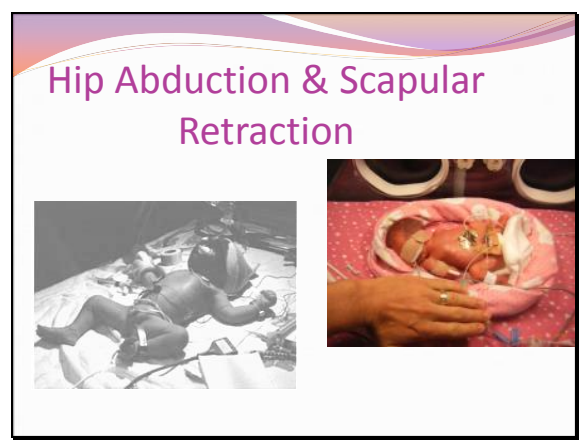

So, here are a couple of the positions that cause musculoskeletal problems. Both of these positions can be easily improved with the use of properly constructed and placed support rolls, and boundaries for containment. 
Slide 17

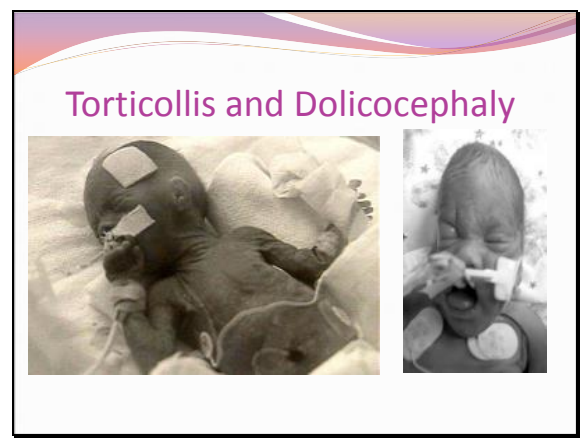

Slide 18

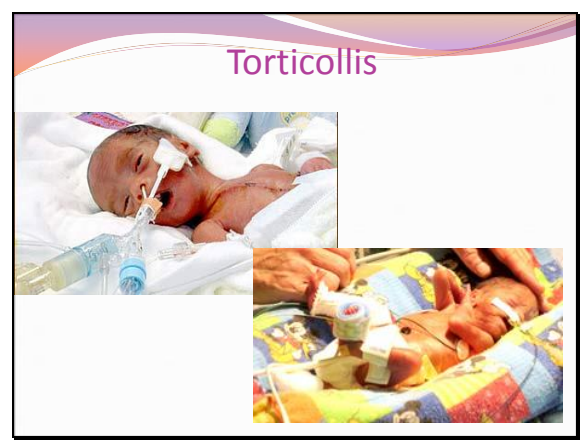

Slide 19

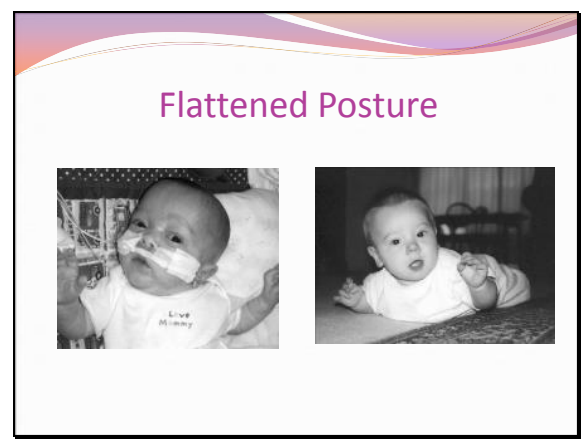

This infant's head position one the left is very common and is the cause of right or left sided head preference or torticollis in older infants. This could be avoided by placing the infant on their side, or providing support for the infant's cheek to make the head and neck aligned. On the right is an example of dolicocephaly which is also the result of predominantly positioning the head to the left or right side.

These two infants have some of the characteristic negative outcomes of not being developmentally positioned. On the left is right sided head preference which we see a lot, as well as the W shape of his arms, rather than a midline orientation. The infant on the right has such severe scapular retraction that his ability to crawl will be delayed. 
Slide 20

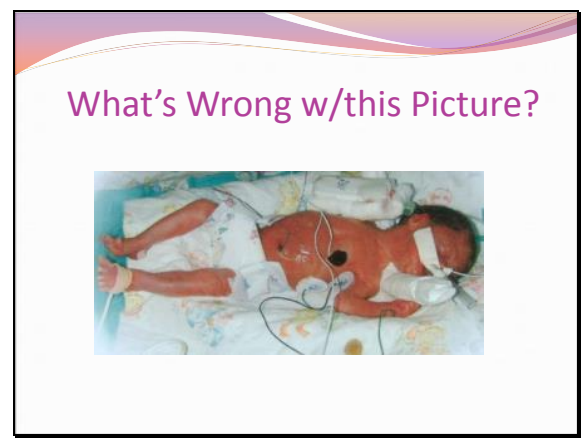

Slide 21

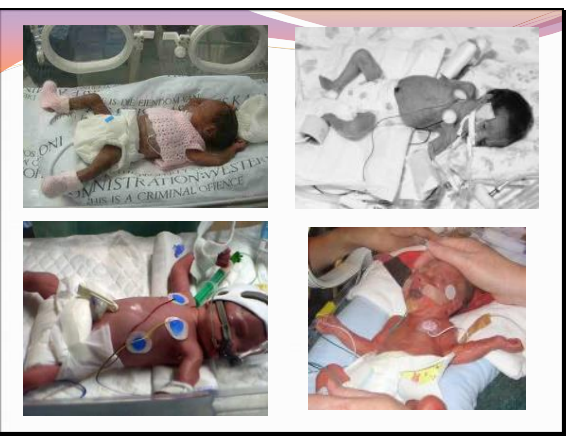

Neck rolls should not be used. The baby should be on their side with their neck in a more neutral position, flexion of the lower extremities and boundaries.

So, there are various things wrong with the infant positioning, however, in all of them, the infants scapular retraction and hip abduction are the most obvious problems. These positions directly contribute to poor musculoskeletal outcomes, as well as potential discomfort and airway issues from not being in a midline and flexed position. The boundaries that are available to these infants are not constructed properly. They need to be higher to facilitate containment. These patients would all benefit by being turned on their side, flexing their extremities, and placing their hands to their mouths. These can all be accomplished with the developmental Snugglies that we have available, by making linen roll supports, and by using a Bendy Bumper. 
Slide 22

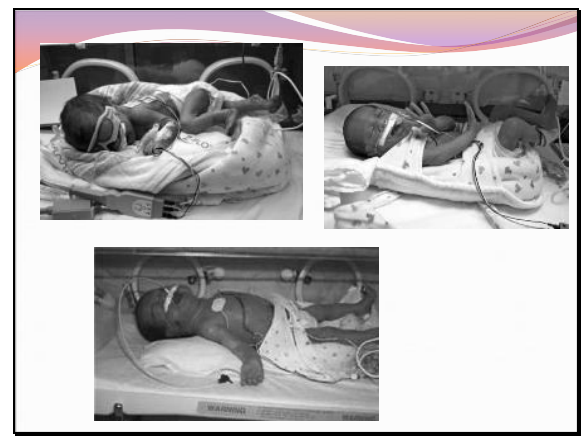

Slide 23

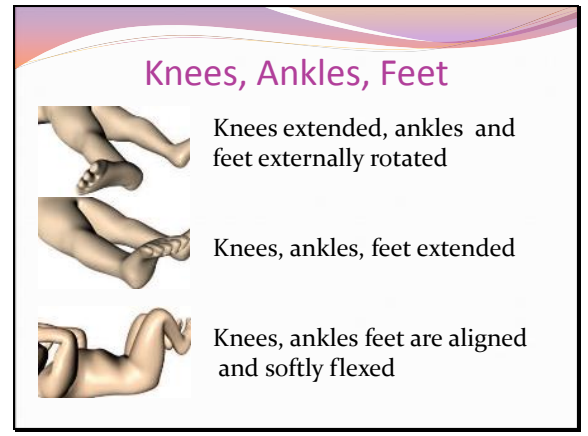

Here is an example of incorrect use of the products. Top left, the linen for torso support is too high, too large, and too wide, and it makes the baby "pop" out of the Snuggle Up; the baby also needs to be tucked in deeper into the pocket of the Snuggle Up, and the prone support needs to be made to fit the baby's size, essentially not as wide, and not as high. On the top right, the legs and arms need to be tucked in the pocket, and the infant should be turned on their side with hands to mouth. On the bottom the baby again needs to be tucked deeper into the pocket; the linen roll needs to be adjusted to support slight flexion of the neck, and rounding of the shoulders. All of these infants would benefit from the use of a Bendy Bumper to provide additional boundaries.

The next few slides contain portions of the IPAT (Infant Position Assessment Tool) that we will be implementing. It is an objective measurement meant to assist with visualizing the desired infant positions. It is also a scoring tool that can be used as an evaluation tool for quality improvement. 
Slide 24

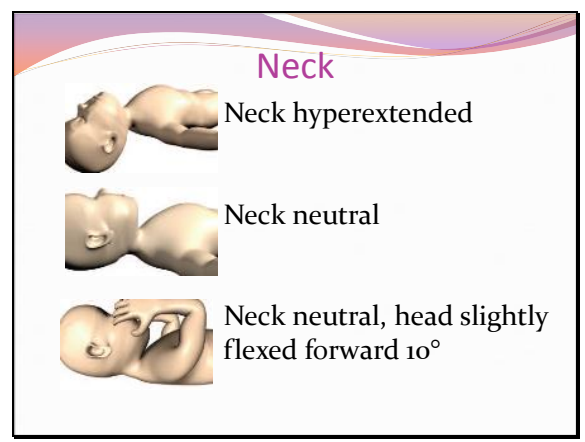

Slide 25

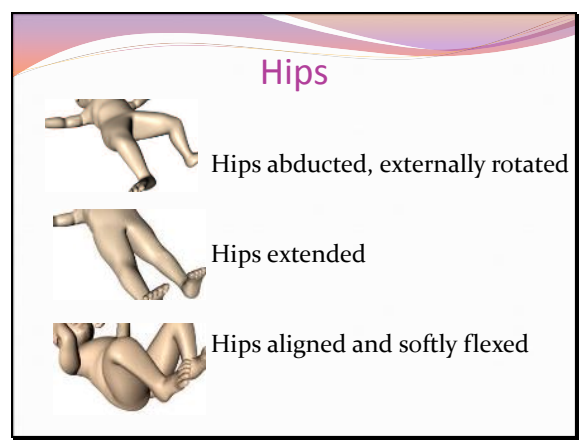

Slide 26

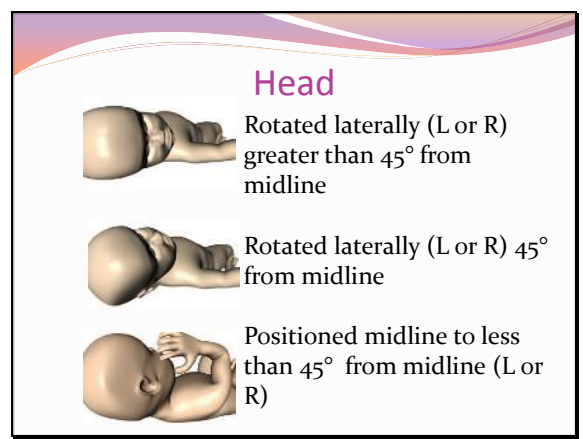

The IPAT has 6 different elements.

Each element is scored on a scale from $0-2$.

A higher score indicates better positioning. 
Slide 27

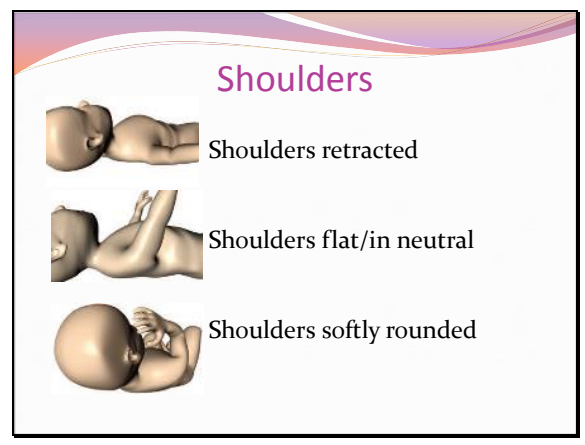

Slide 28

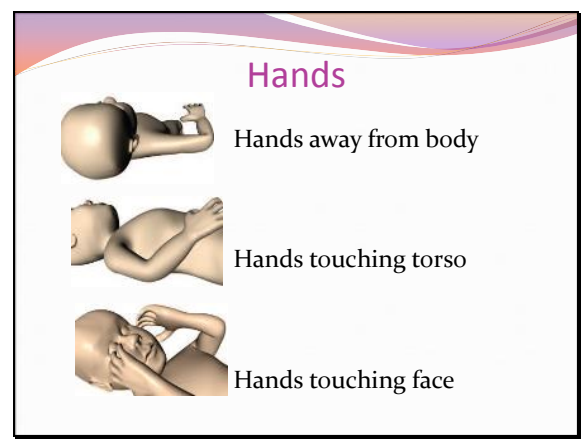

Slide 29

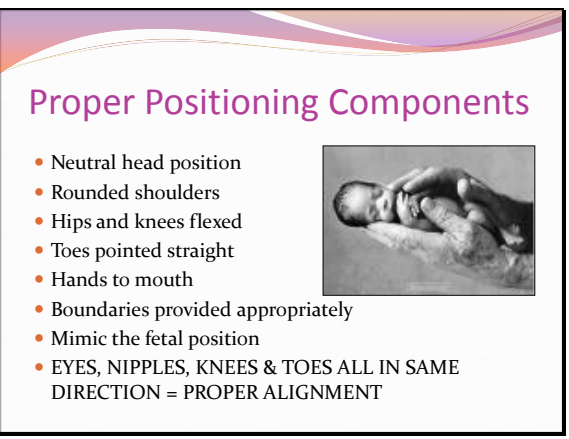

An ideal score is 10-12.

Be on the lookout for these IPAT tools at your bedside.
So, now that we know what not to do, let's talk about what to do. One of the goals of developmental positioning is to maintain a midline orientation - the IPAT will assist you with the optimal position of each part of the baby, so keep an eye out for that tool. The second goal is to promote normal developmental by providing boundaries and postural supports. 
Slide 30

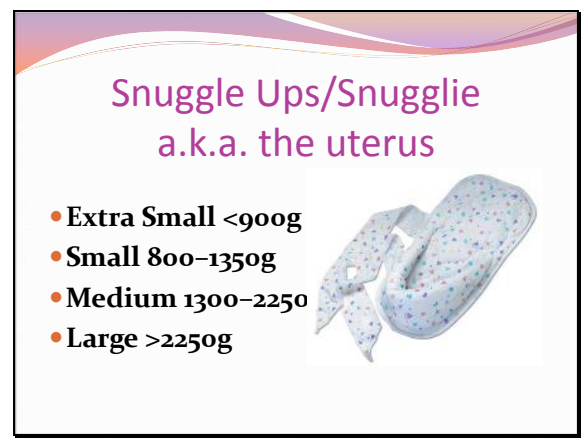

Slide 31

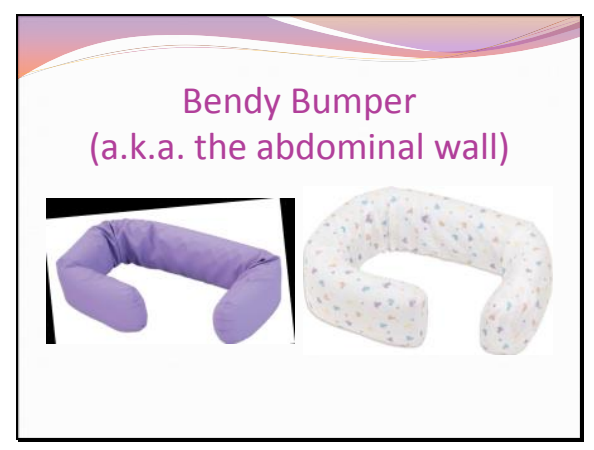

Slide 32

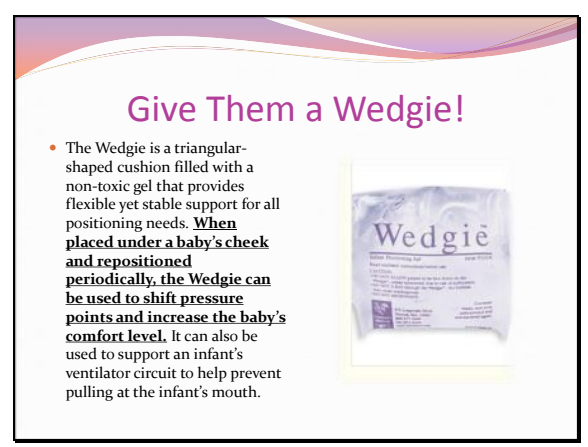

Snuggle Ups come in a variety of sizes, so make sure that you choose the correct size for your infant's weight. This is meant to simulate the uterus.

The Snuggle Up is like the uterus, and the Bendy Bumper is like the abdominal wall muscle. They are great for babies who are very active, as they add support to the outside of the Snuggle Up and keeps the babies more contained. Make sure that the linen supports or gel pillows are not too high, or use the larger size Bendy Bumper to compensate for the height.

These are greatly underused in our unit, and they are very helpful for supporting ventilator circuits or other large tubes, and for supporting the head in a midline position when the baby is supine or side lying. 
Slide 33

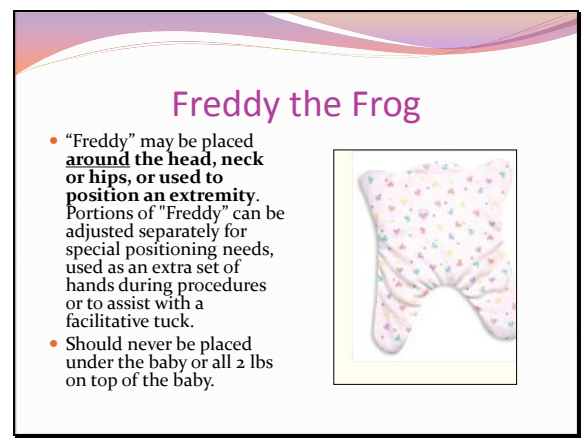

Slide 34

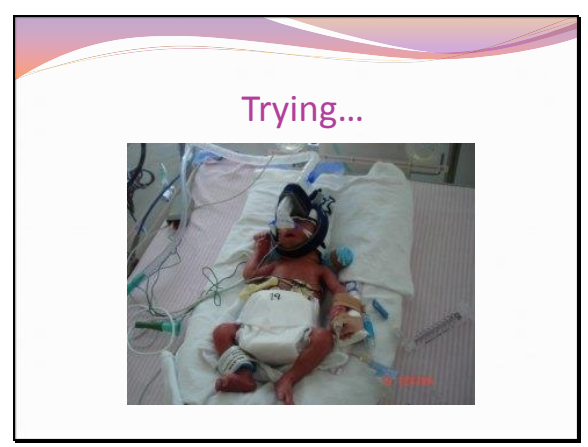

Slide 35

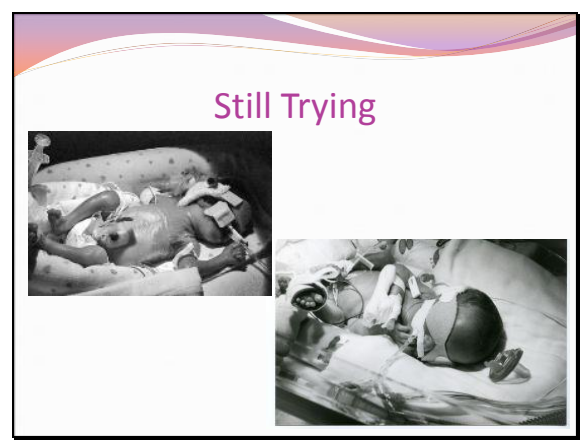

Freddy the Frog is another great tool for providing support and containment around the head. It can also support extremities as needed.
This baby's position is a slight improvement from previous examples, but he or she would still benefit from rolls to round the shoulders, adduction of the hips, and a Snuggle Up to promote flexion and provide boundaries.
In these photos, the infants need to be moved more fully onto their sides with their shoulders rounded. The hand to mouth orientation is pretty good here. 
Slide 36

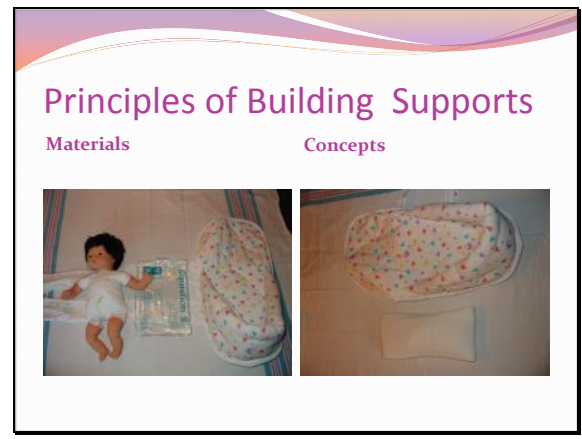

Slide 37

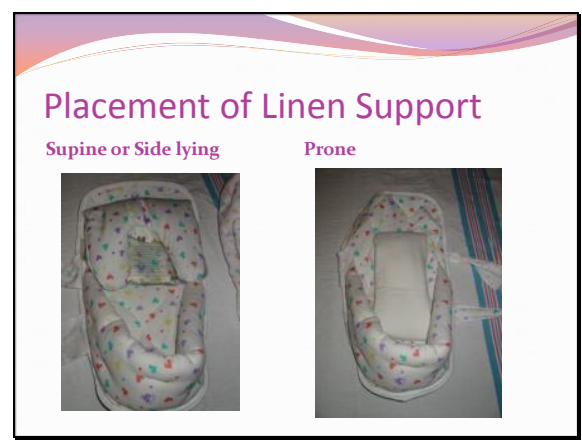

Slide 38

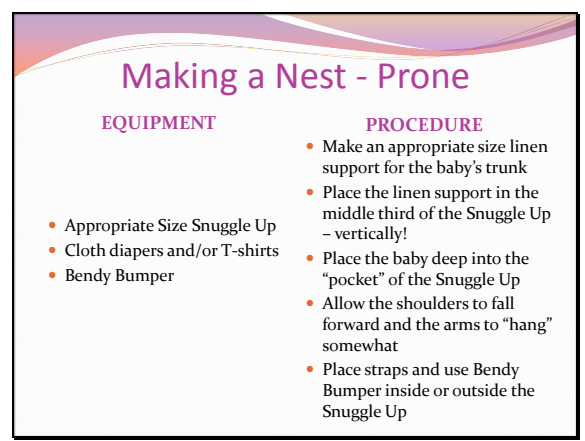

No matter what materials you use to build the supports (gel pillows or linen rolls) a few principles need to be kept in mind. First, the materials should be the appropriate size. For example, a 500 gram infant, you will likely use t-shirts, rather than a cloth diaper for their supports. Second, the support needs to be built to the proper height and size in order to facilitate the fetal position.

One of the things we need to work on is the placement of the gel pillows or linen supports. If the infant is supine or sidelying, the goal of the supports is to round the shoulders forward, so place the support horizontally behind both their head and their neck. If the infant is prone, place the support vertically and under their head, chest and abdomen.

These are the basics of making a nest for an infant in the prone position. 
Slide 39

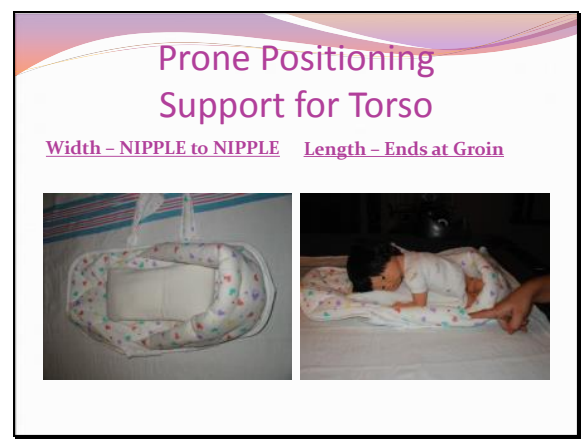

Slide 40

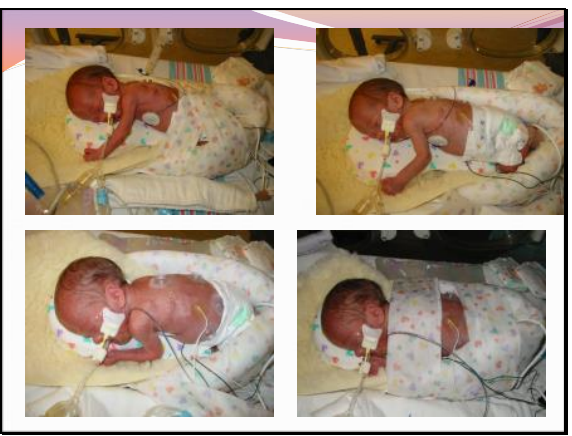

In the prone position, you may need to use two t-shirts rolled together, or two cloth diapers folded together in order to get the lift needed to allow the shoulders to fall forward and the hips to tuck under. The supports for the prone positioning need to be arranged to have a width that is approximately nipple to nipple and a height that allows the infant's shoulders to round forward, and to allow the hips to tuck under. The support should end at the groin to facilitate tucking of the hips. The support can extend above the head, and Freddy the Frog can be used around the head for support.

Very often, a small adjustment is all that is needed to properly position the baby. This baby went from being fussy with labile FiO2 needs, to asleep within moments of being properly positioned. These prone positioners are not available, but again the same position can be accomplished with linen roll supports. 
Slide 41

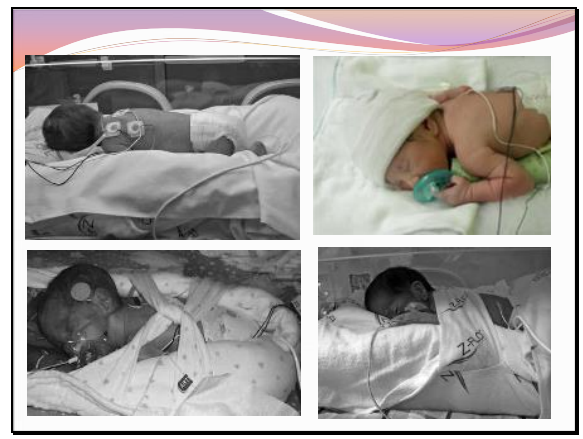

Slide 42

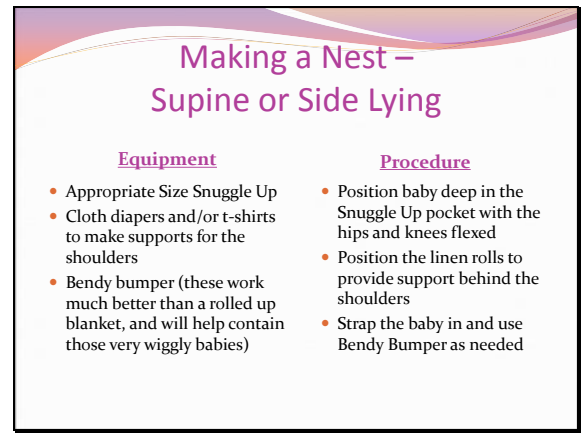

These infants are well positioned and contained. Their linens supports allow for rounding of the shoulders, but are not so high that the infants are popping out of their nests. They are tucked well into the Snuggle Up pocket, and the straps are used to maintain the containment. We can also see appropriate positioning of the lower extremities in the two photos on the left. The prone position is often overused however, and it causes undue stress on the airway and neck and results in torticollis. We should limit the use of the prone position if possible. Unless the infant has respiratory or GI issues that are significantly impaired by the supine or side-lying position, we should place them in those positions more often than the prone position.

This is the basic idea behind making a nest for a supine or side-lying infant. 
Slide 43

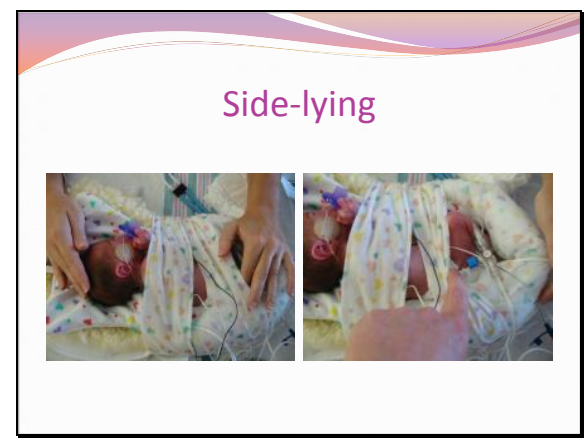

Slide 44

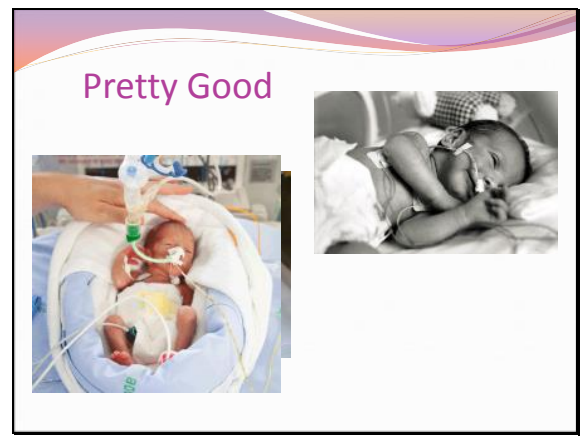

You can use Freddy the Frog to help keep the support in place around the babies head. Freddy is not a pillow however, so please don't place them under the babies head. In these pictures, you can also see the flexion and containment of the extremities. This baby is well positioned, deep in the pocket of the Snugglie, midline, and with flexion and containment. The IV can still be assessed by pulling out the leg. An IV in an extremity is not a contraindication to developmental positioning. It just requires a little more work to view the IV.

These babies are also positioned pretty well. The baby on the left has good boundaries and flexion, but could benefit from placing her head more midline, and bringing her hands to her mouth. Again, a tube in the mouth is not a contraindication for developmental positioning, but requires a shift in the nurses thinking - does the baby grab the tube? What kind of tube is it? Is the tube secure? Does the baby need sedation or pain control? How can I balance safety and the developmental needs of the baby?

The baby on the right would benefit from a roll behind the right shoulder, and moving the linen roll under her head down to support her neck a bit more. 
Slide 45

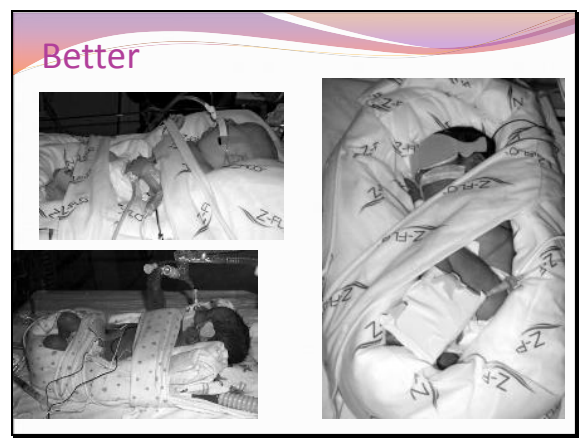

Slide 46

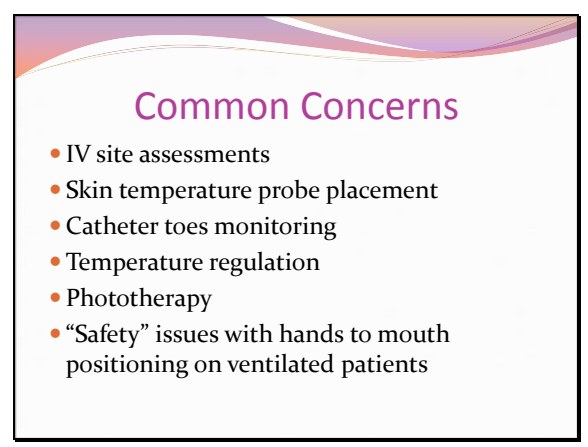

These infants are very well positioned, except the tubes could be supported a bit more. Using the straps greatly enhances the containment, and the straps can be twisted or maneuvered to allow exposure to areas that need to be uncovered (phototherapy and temperature probes for example).

These are some of the concerns NICU nurses have when it comes to developmental positioning. Although these situations do require consideration and planning, they are not significant enough reasons to prevent positioning the infants in a developmentally supportive manner. These situations require a different way of thinking and practicing, as well as the belief that the risk/benefit ratio favors developmental positioning. The research fully supports developmental positioning and after using it during your care, I am hopeful that these concerns will become less of an issue. 
Slide 47

\begin{tabular}{|c|c|}
\hline \multicolumn{2}{|c|}{ Thank You! } \\
\hline $\begin{array}{l}\text { And a big thank } \\
\text { you to our } \\
\text { developmental } \\
\text { positioning } \\
\text { team: }\end{array}$ & $\begin{array}{l}\text { - Katie Church } \\
\text { - Diane Crothers } \\
\text { - Jennifer McDonald } \\
\text { - Jill Pfeiffer } \\
\text { - Helene Rabajante } \\
\text { - Nicole Rohde } \\
\text { - Kelly Ryan } \\
\text { - Kat Quaile }\end{array}$ \\
\hline
\end{tabular}

Thank you so much for taking the time to view this presentation! Please look for other resources around the unit, and feel free to consult with me or with the experts on our developmental positioning team. Thank you to all of them for their work with this project. It would not have happened without their support, and I am hopeful that this education results in positive change for our patients and ourselves. 


\section{APPENDIX D: INTER-RATER RELIABILITY STATISTICS}

RELIABILITY

/VARIABLES=Rater1 Rater2 Rater3 Rater4 Rater5 Rater6 Rater7 Rater8 Rater9

/SCALE('ALL VARIABLES') ALL

/MODEL=ALPHA

$/$ ICC=MODEL(MIXED) TYPE(CONSISTENCY) CIN=95 TESTVAL=0.

\section{Reliability: Consistency}

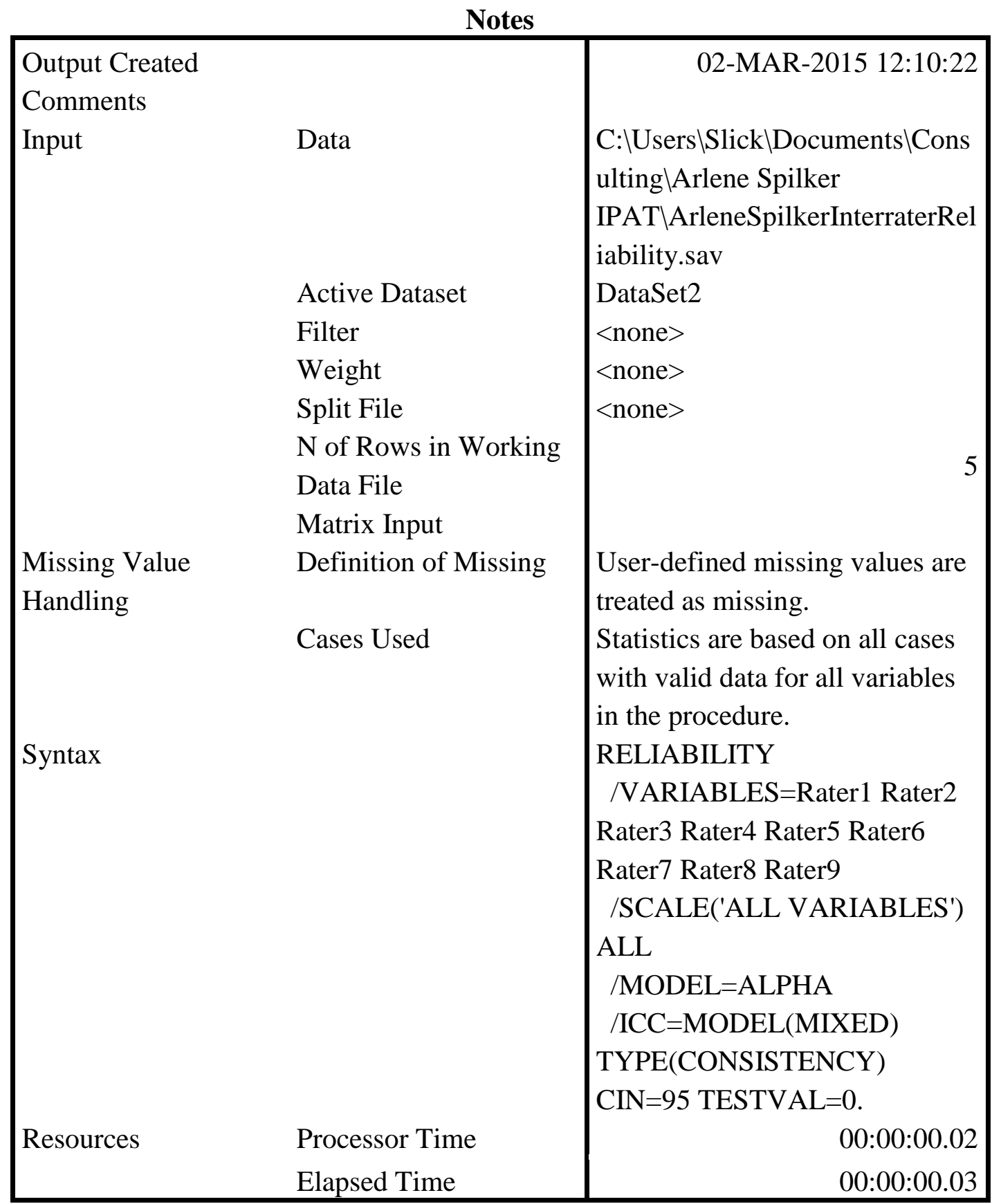


Scale: ALL VARIABLES

\section{Case Processing Summary}

\begin{tabular}{|ll|r|r|}
\hline & & $\mathrm{N}$ & \multicolumn{1}{|c|}{$\%$} \\
\hline Cases & Valid & 5 & 100.0 \\
& Excluded $^{\mathrm{a}}$ & 0 & .0 \\
& Total & 5 & 100.0 \\
\hline
\end{tabular}

a. Listwise deletion based on all variables in the procedure.

\begin{tabular}{|r|r|}
\multicolumn{2}{c|}{ Reliability Statistics } \\
\hline $\begin{array}{c}\text { Cronbach's } \\
\text { Alpha }\end{array}$ & N of Items \\
\hline .972 & 9 \\
\hline
\end{tabular}

Intraclass Correlation Coefficient

\begin{tabular}{|c|c|c|c|c|c|c|}
\hline & \multirow[b]{2}{*}{$\begin{array}{c}\text { Intraclass } \\
\text { Correlation }^{\mathrm{b}}\end{array}$} & \multicolumn{2}{|c|}{ 95\% Confidence Interval } & \multicolumn{3}{|c|}{ F Test with True Value 0} \\
\hline & & $\begin{array}{l}\text { Lower } \\
\text { Bound }\end{array}$ & $\begin{array}{l}\text { Upper } \\
\text { Bound }\end{array}$ & Value & df1 & df2 \\
\hline Single Measures & $.797^{\mathrm{a}}$ & .533 & .971 & 36.227 & 4 & 32 \\
\hline $\begin{array}{l}\text { Average } \\
\text { Measures }\end{array}$ & $.972^{\mathrm{c}}$ & .911 & .997 & 36.227 & 4 & 32 \\
\hline
\end{tabular}

Intraclass Correlation Coefficient

\begin{tabular}{|l|r|}
\hline & \multicolumn{2}{|c|}{ F Test with True Value 0 } \\
\cline { 2 - 2 } & \multicolumn{1}{|c|}{ Sig } \\
\hline Single Measures & .000 \\
Average Measures & .000 \\
\hline
\end{tabular}

Two-way mixed effects model where people effects are random and measures effects are fixed.

a. The estimator is the same, whether the interaction effect is present or not.

b. Type $\mathrm{C}$ intraclass correlation coefficients using a consistency definition. The betweenmeasure variance is excluded from the denominator variance.

c. This estimate is computed assuming the interaction effect is absent, because it is not estimable otherwise. 


\author{
RELIABILITY \\ /VARIABLES=Rater1 Rater2 Rater3 Rater4 Rater5 Rater6 Rater7 Rater8 Rater9 \\ /SCALE('ALL VARIABLES') ALL \\ $/ \mathrm{MODEL}=\mathrm{ALPHA}$ \\ /ICC=MODEL(MIXED) TYPE(ABSOLUTE) CIN=95 TESTVAL=0.
}

Reliability: Absolute

\section{Notes}

\begin{tabular}{|c|c|c|}
\hline \multicolumn{2}{|l|}{$\begin{array}{l}\text { Output Created } \\
\text { Comments }\end{array}$} & 02-MAR-2015 12:10:39 \\
\hline & $\begin{array}{l}\text { Active Dataset } \\
\text { Filter } \\
\text { Weight } \\
\text { Split File } \\
\mathrm{N} \text { of Rows in Working } \\
\text { Data File } \\
\text { Matrix Input }\end{array}$ & $\begin{array}{l}\text { C:IUsers\Slick\Documents\Cons } \\
\text { ulting\Arlene Spilker } \\
\text { IPAT\ArleneSpilkerInterraterRel } \\
\text { iability.sav } \\
\text { DataSet2 } \\
\text { <none> } \\
\text { <none> } \\
\text { <none> }\end{array}$ \\
\hline $\begin{array}{l}\text { Missing Value } \\
\text { Handling }\end{array}$ & Definition of Missing & $\begin{array}{l}\text { User-defined missing values are } \\
\text { treated as missing. }\end{array}$ \\
\hline & Cases Used & $\begin{array}{l}\text { Statistics are based on all cases } \\
\text { with valid data for all variables } \\
\text { in the procedure. }\end{array}$ \\
\hline Syntax & & $\begin{array}{l}\text { RELIABILITY } \\
\text { /VARIABLES=Rater1 Rater2 } \\
\text { Rater3 Rater4 Rater5 Rater6 } \\
\text { Rater7 Rater8 Rater9 } \\
\text { /SCALE('ALL VARIABLES') } \\
\text { ALL } \\
\text { /MODEL=ALPHA } \\
\text { /ICC=MODEL(MIXED) } \\
\text { TYPE(ABSOLUTE) CIN=95 } \\
\text { TESTVAL=0. }\end{array}$ \\
\hline Resources & $\begin{array}{l}\text { Processor Time } \\
\text { Elapsed Time }\end{array}$ & $\begin{array}{l}\text { 00:00:00.02 } \\
\text { 00:00:00.02 }\end{array}$ \\
\hline
\end{tabular}


Scale: ALL VARIABLES

\section{Case Processing Summary}

\begin{tabular}{|ll|r|r|}
\hline & & N & \multicolumn{1}{|c|}{$\%$} \\
\hline Cases & Valid $^{2}$ & 5 & 100.0 \\
& Excluded $^{\mathrm{a}}$ & 0 & .0 \\
& Total & 5 & 100.0 \\
\hline
\end{tabular}

a. Listwise deletion based on all variables in the procedure.

\section{Reliability Statistics}

\begin{tabular}{|c|r|}
\hline $\begin{array}{c}\text { Cronbach's } \\
\text { Alpha }\end{array}$ & N of Items \\
\hline .972 & 9 \\
\hline
\end{tabular}

Intraclass Correlation Coefficient

\begin{tabular}{|l|r|r|r|r|r|r|}
\hline & & \multicolumn{2}{|c|}{$95 \%$ Confidence Interval } & \multicolumn{3}{|c|}{ F Test with True Value 0 } \\
\cline { 3 - 8 } & $\begin{array}{c}\text { Intraclass } \\
\text { Correlation }^{\mathrm{b}}\end{array}$ & $\begin{array}{c}\text { Lower } \\
\text { Bound }\end{array}$ & $\begin{array}{c}\text { Upper } \\
\text { Bound }\end{array}$ & Value & \multicolumn{1}{c|}{ df1 } & \multicolumn{1}{c|}{ df2 } \\
\hline Single Measures & $.712^{\mathrm{a}}$ & .411 & .956 & 36.227 & 4 & 32 \\
Average & $.957^{\mathrm{c}}$ & .863 & .995 & 36.227 & 4 & 32 \\
Measures & & & & &
\end{tabular}

Intraclass Correlation Coefficient

\begin{tabular}{|l|r|}
\hline & \multicolumn{2}{|c|}{ F Test with True Value $0^{\mathrm{b}}$} \\
\cline { 2 - 3 } & \multicolumn{2}{|c|}{ Sig } \\
\hline Single Measures & .000 \\
Average Measures & .000 \\
\hline
\end{tabular}

Two-way mixed effects model where people effects are random and measures effects are fixed.

a. The estimator is the same, whether the interaction effect is present or not.

b. Type A intraclass correlation coefficients using an absolute agreement definition.

c. This estimate is computed assuming the interaction effect is absent, because it is not estimable otherwise. 


\section{APPENDIX E: IPAT SCORE ANALYSIS}

NEW FILE.

DATASET NAME DataSet2 WINDOW=FRONT.

T-TEST GROUPS=Condition('Pre' 'Post')

/MISSING=ANALYSIS

/VARIABLES=TotalIPAT

/CRITERIA $=\mathrm{CI}(.95)$.

\section{T-Test}

\section{Notes}

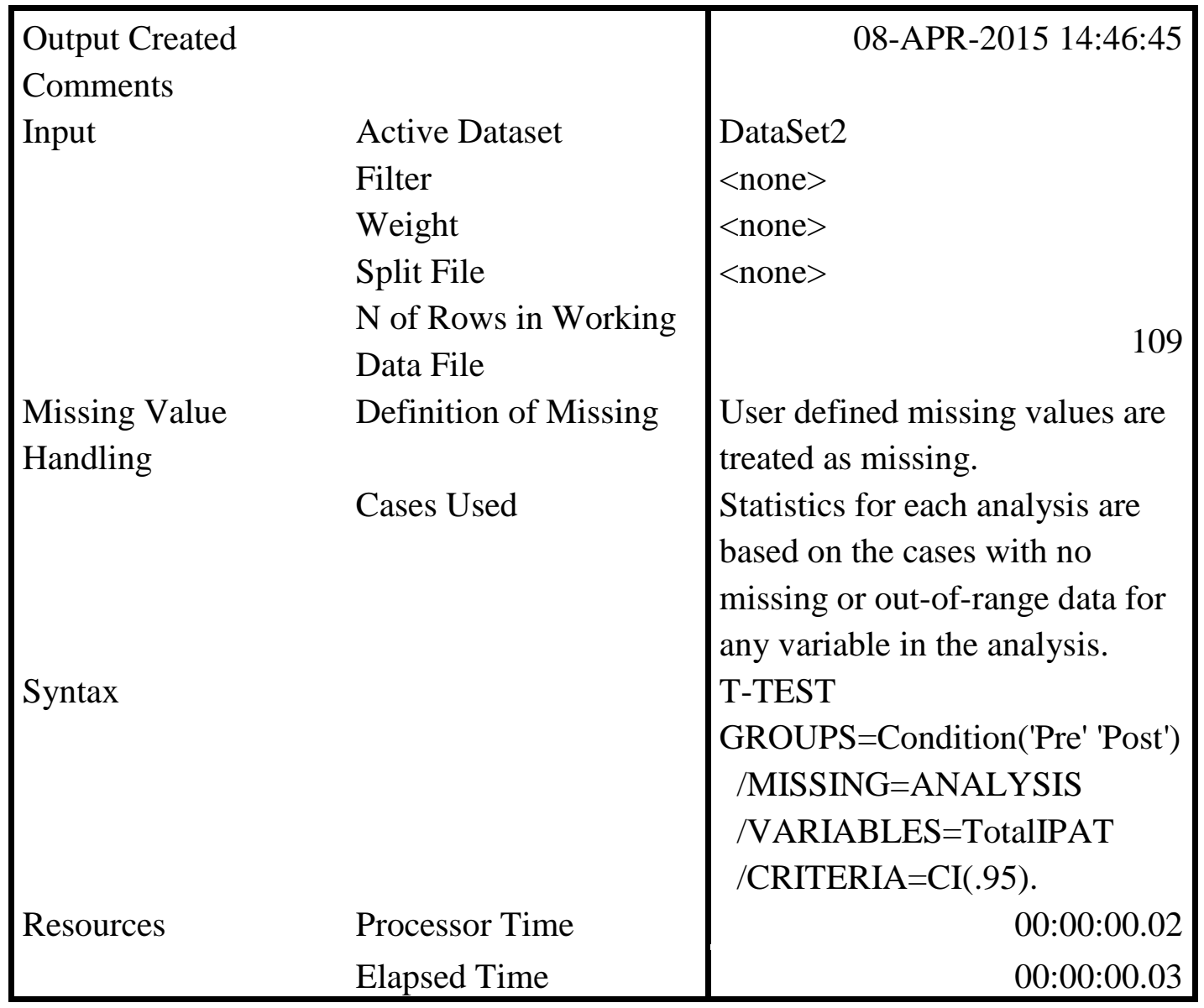

[DataSet2] 


\begin{tabular}{|ll|r|r|r|c|}
\hline \multicolumn{1}{|c|}{ Group Statistics } \\
& Condition & $\mathrm{N}$ & Mean & $\begin{array}{c}\text { Std. } \\
\text { Deviation }\end{array}$ & $\begin{array}{c}\text { Std. Error } \\
\text { Mean }\end{array}$ \\
\hline TotalIPA & Pre & 54 & 8.3889 & 2.49843 & .33999 \\
$\mathrm{~T}$ & Post & 55 & 9.4182 & 2.28271 & .30780 \\
\hline
\end{tabular}

Independent Samples Test

\begin{tabular}{|c|c|c|c|c|c|}
\hline & \multicolumn{2}{|c|}{$\begin{array}{c}\text { Levene's Test for Equality of } \\
\text { Variances } \\
\end{array}$} & \multicolumn{2}{|c|}{$\begin{array}{c}\text { t-test for Equality } \\
\text { of Means }\end{array}$} \\
\hline & & $\mathrm{F}$ & Sig. & $\mathrm{t}$ & $\mathrm{df}$ \\
\hline $\begin{array}{l}\text { TotalIPA } \\
\mathrm{T}\end{array}$ & $\begin{array}{l}\text { Equal variances } \\
\text { assumed } \\
\text { Equal variances not } \\
\text { assumed }\end{array}$ & 1.546 & .217 & $\begin{array}{l}-2.246 \\
-2.244\end{array}$ & $\begin{array}{r}107 \\
105.755\end{array}$ \\
\hline
\end{tabular}

\section{Independent Samples Test}

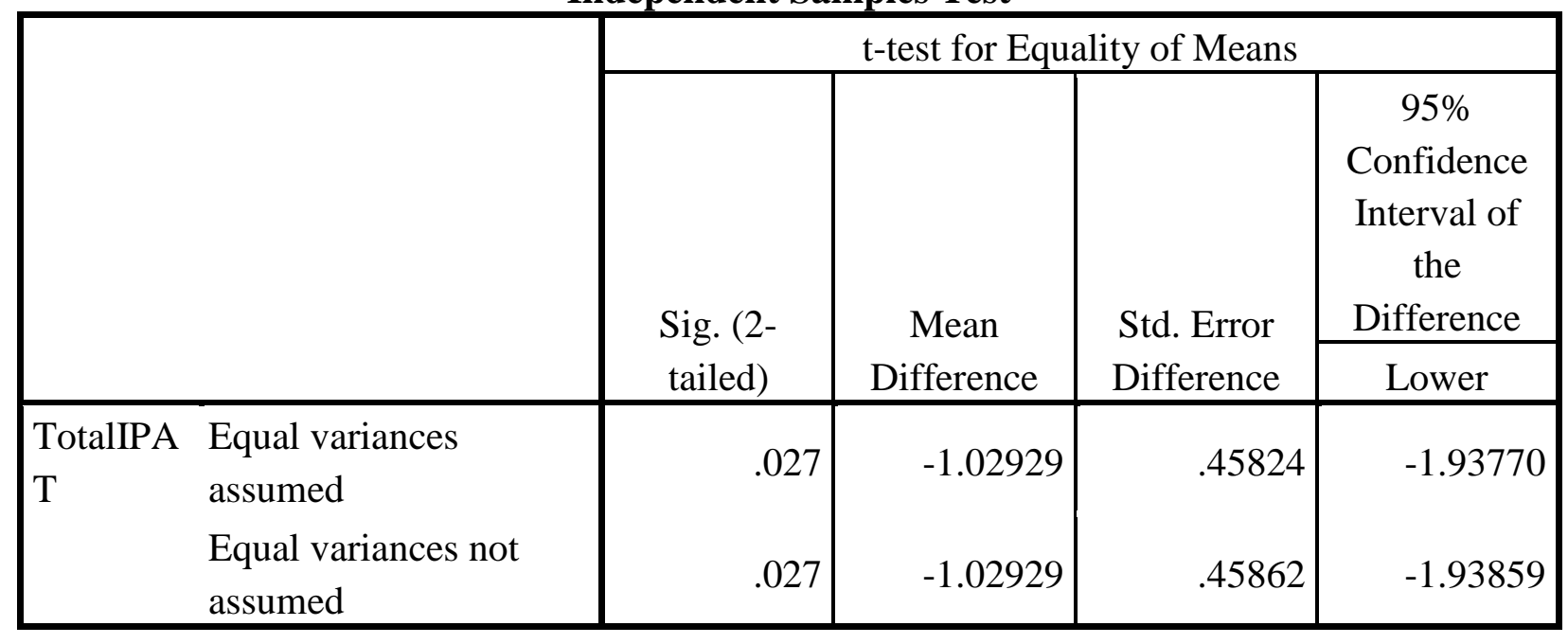

Independent Samples Test

\begin{tabular}{|c|c|c|}
\hline & & $\begin{array}{l}\text { t-test for Equality of } \\
\text { Means }\end{array}$ \\
\hline & & $\begin{array}{c}95 \% \text { Confidence Interval } \\
\text { of the Difference }\end{array}$ \\
\hline & & Upper \\
\hline TotalIPAT & Equal variances assumed & -.12088 \\
\hline & Equal variances not assumed & -.12000 \\
\hline
\end{tabular}




\section{APPENDIX F: NURSES SURVEY RESULTS}

\section{Initial Report}

Last Modified: 04/10/2015

1. What is your age?

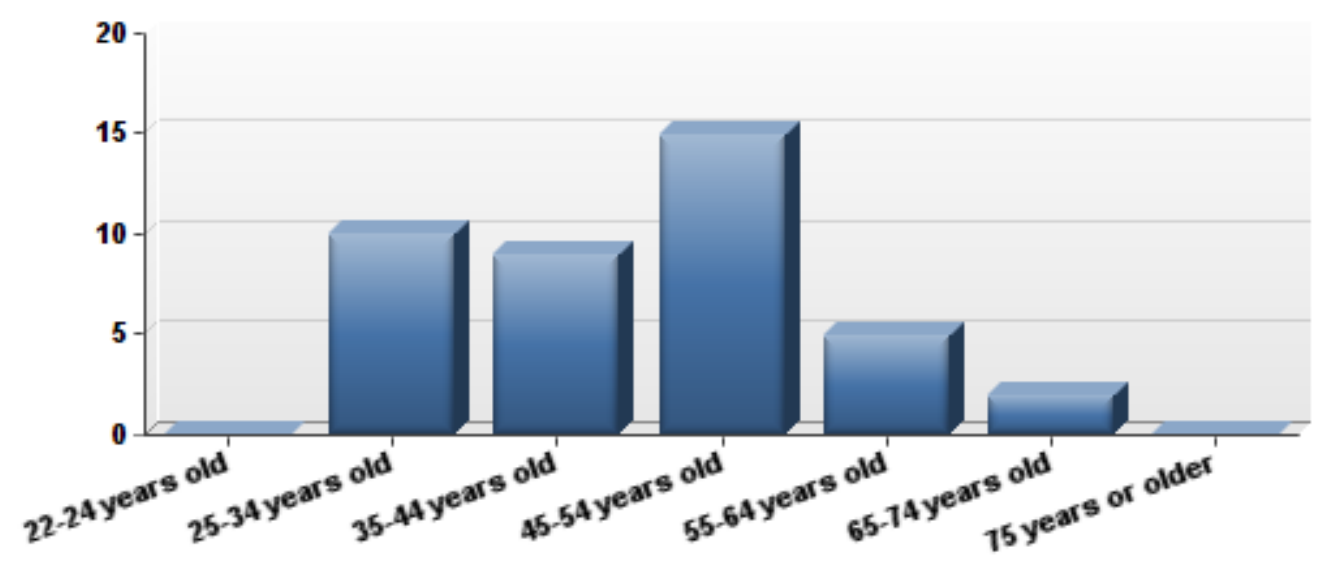




\begin{tabular}{|c|c|c|c|}
\hline \# & Answer & Response & $\%$ \\
\hline 1 & $\begin{array}{l}\text { 22-24 years } \\
\text { old }\end{array}$ & 0 & $0 \%$ \\
\hline 2 & $\begin{array}{l}25-34 \text { years } \\
\text { old }\end{array}$ & 10 & $24 \%$ \\
\hline 3 & $\begin{array}{l}35-44 \text { years } \\
\text { old }\end{array}$ & 9 & $22 \%$ \\
\hline 4 & $\begin{array}{l}45-54 \text { years } \\
\text { old }\end{array}$ & 15 & $37 \%$ \\
\hline 5 & $\begin{array}{l}55-64 \text { years } \\
\text { old }\end{array}$ & 5 & $12 \%$ \\
\hline 6 & $\begin{array}{l}65-74 \text { years } \\
\text { old }\end{array}$ & 2 & $5 \%$ \\
\hline 7 & $\begin{array}{l}75 \text { years or } \\
\text { older }\end{array}$ & 0 & $0 \%$ \\
\hline & Total & 41 & $100 \%$ \\
\hline
\end{tabular}

Statistic

Min Value

Max Value

Mean

Variance

Standard Deviation

Total Responses
Value 


\section{Please specify your ethnicity.}

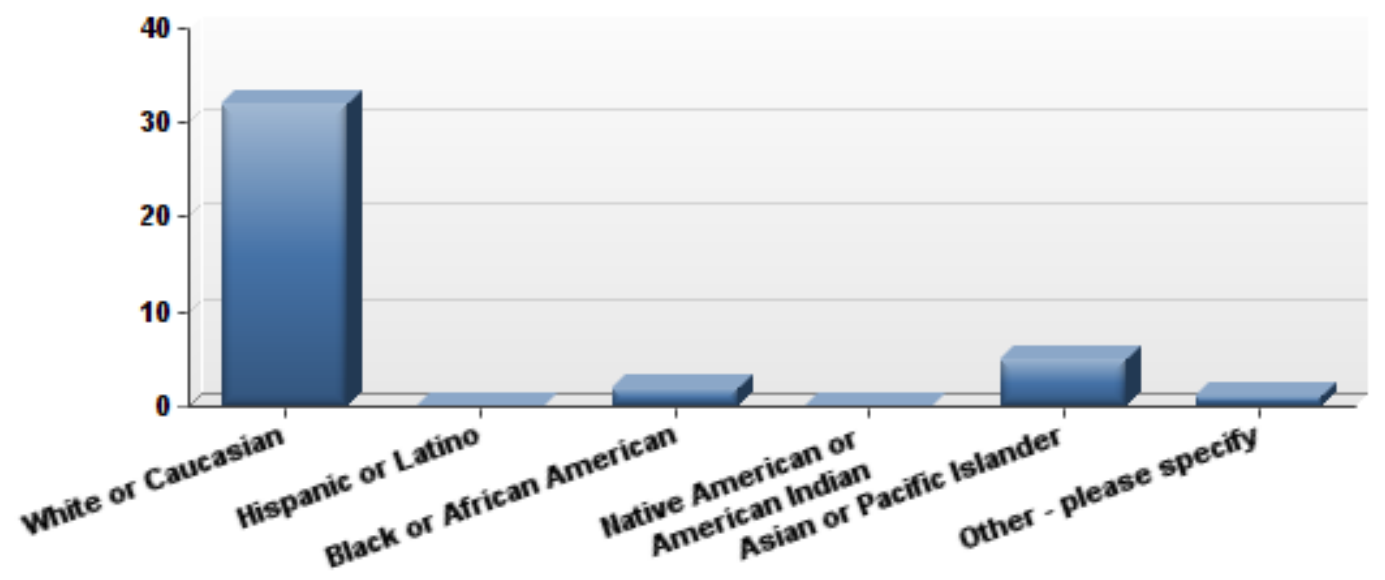

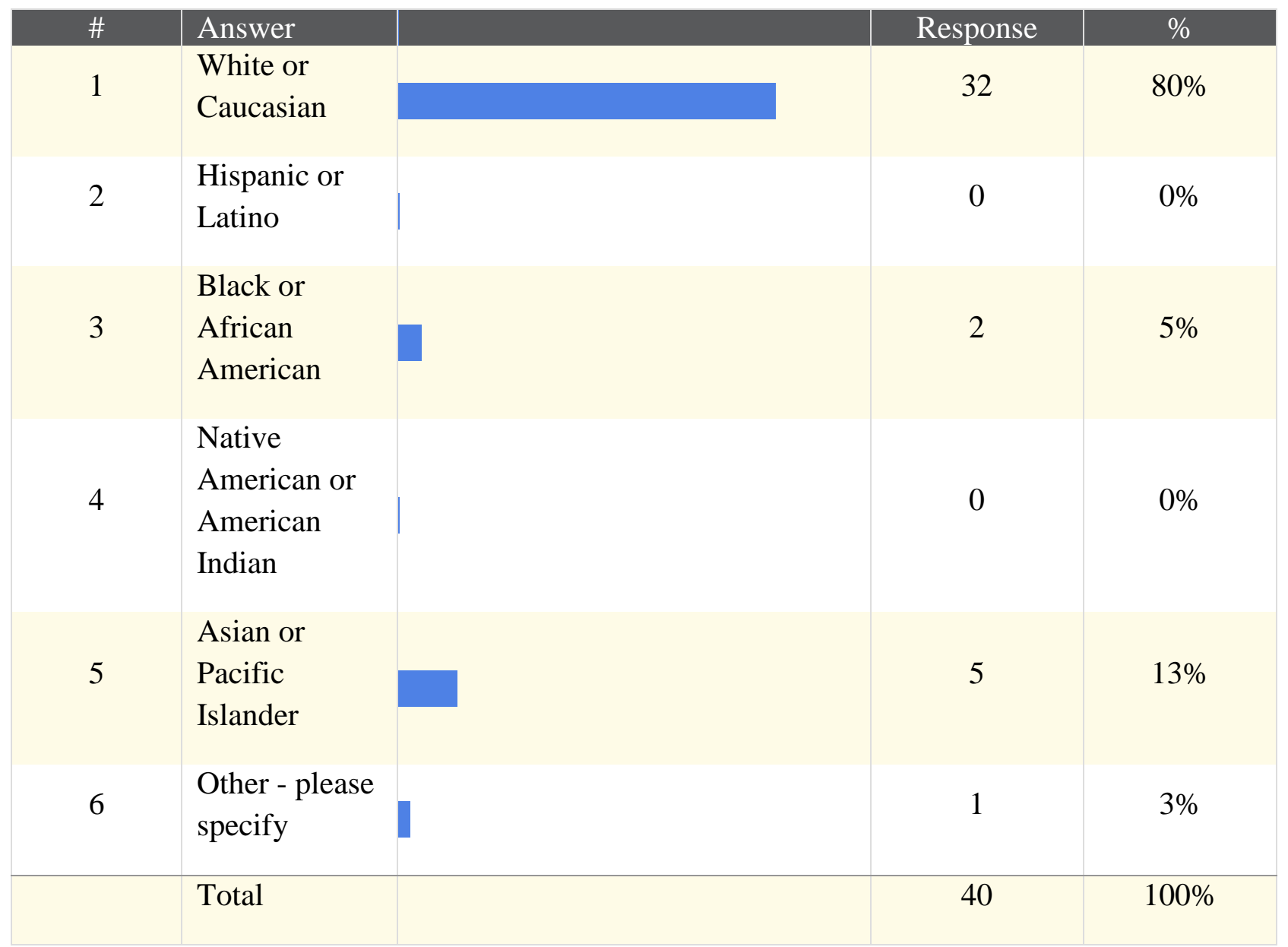


Other - please specify

Persian

Statistic

Value

Min Value

Max Value

Mean

Variance

Standard Deviation

Total Responses

\section{What is your highest level of education?}

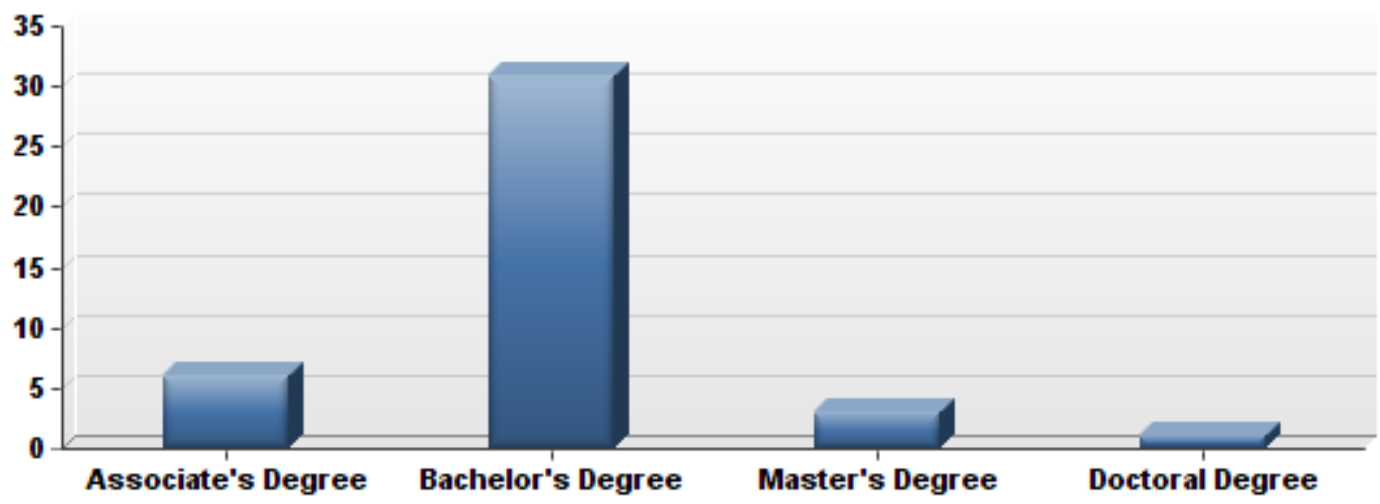




\begin{tabular}{|c|l|c|c|c|}
\hline$\#$ & Answer & & Response & $\%$ \\
\hline 1 & $\begin{array}{l}\text { Associate's } \\
\text { Degree }\end{array}$ & & 6 & $15 \%$ \\
\hline 2 & $\begin{array}{l}\text { Bachelor's } \\
\text { Degree }\end{array}$ & & 31 & $76 \%$ \\
\hline 3 & $\begin{array}{l}\text { Master's } \\
\text { Degree }\end{array}$ & & 3 & $7 \%$ \\
\hline 4 & $\begin{array}{l}\text { Doctoral } \\
\text { Degree }\end{array}$ & & 1 & $2 \%$ \\
\hline
\end{tabular}

Statistic

Min Value

Max Value

Mean

Variance

0.32

Standard Deviation

0.57

Total Responses 


\section{What is your marital status?}

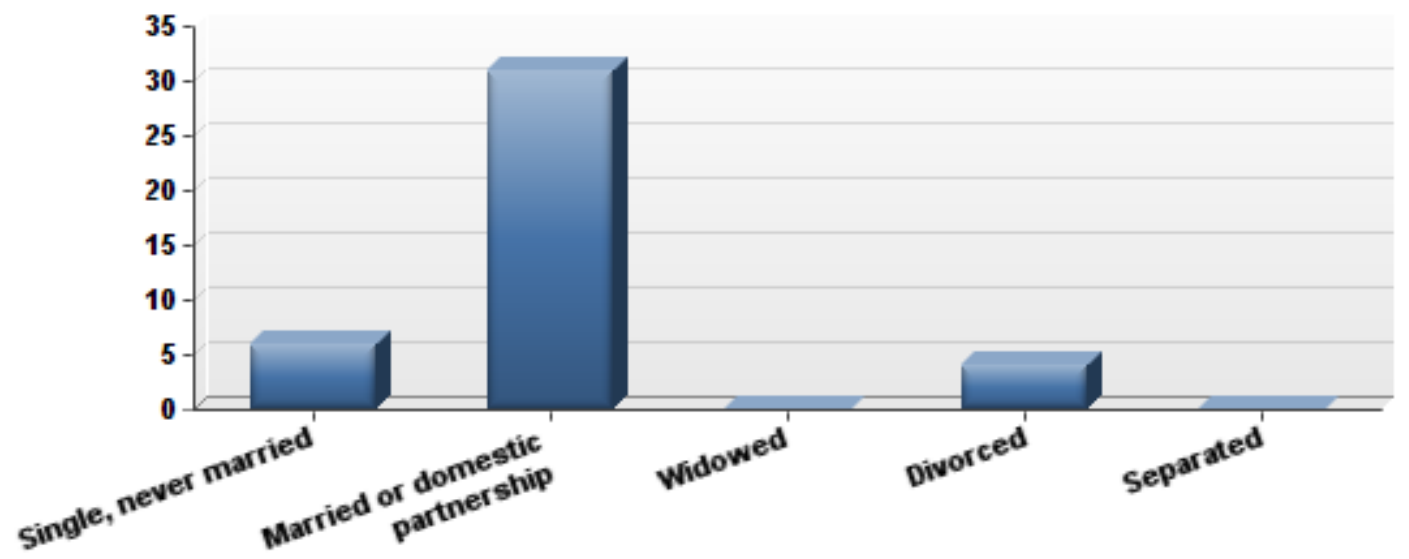

\begin{tabular}{|c|l|l|c|c|}
\hline$\#$ & Answer & & Response & $\%$ \\
\hline 1 & $\begin{array}{l}\text { Single, never } \\
\text { married }\end{array}$ & & 6 & $15 \%$ \\
\hline 2 & $\begin{array}{l}\text { Married or } \\
\text { domestic } \\
\text { partnership }\end{array}$ & & 31 & $76 \%$ \\
\hline 3 & Widowed & & 0 & $0 \%$ \\
\hline 4 & Divorced & & 4 & $10 \%$ \\
\hline 5 & Separated & & 0 & $0 \%$ \\
\hline
\end{tabular}


Statistic

Min Value

Max Value

Mean

Variance

0.55

Standard Deviation

0.74

Total Responses

\section{What is your employment status?}

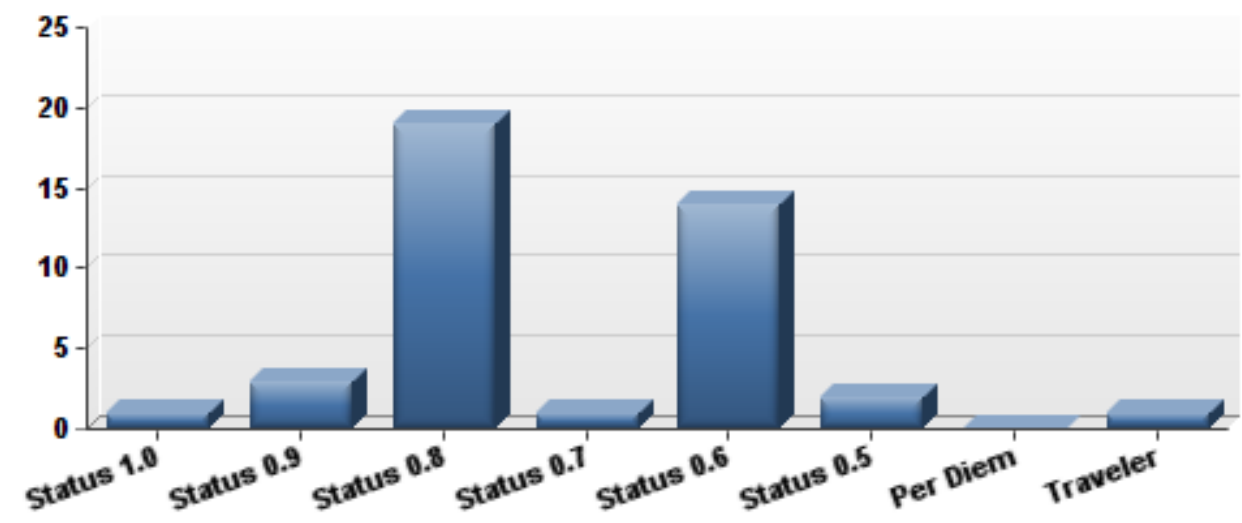




\begin{tabular}{|c|c|c|c|}
\hline \# & Answer & Response & $\%$ \\
\hline 1 & Status 1.0 & 1 & $2 \%$ \\
\hline 2 & Status 0.9 & 3 & $7 \%$ \\
\hline 3 & Status 0.8 & 19 & $46 \%$ \\
\hline 4 & Status 0.7 & 1 & $2 \%$ \\
\hline 5 & Status 0.6 & 14 & $34 \%$ \\
\hline 6 & Status 0.5 & 2 & $5 \%$ \\
\hline 7 & Per Diem & 0 & $0 \%$ \\
\hline \multirow[t]{2}{*}{8} & Traveler & 1 & $2 \%$ \\
\hline & Total & 41 & $100 \%$ \\
\hline
\end{tabular}

Statistic

Value

Min Value

Max Value

Mean

Variance

Standard Deviation

Total Responses 


\section{How many years have you been a registered nurse?}

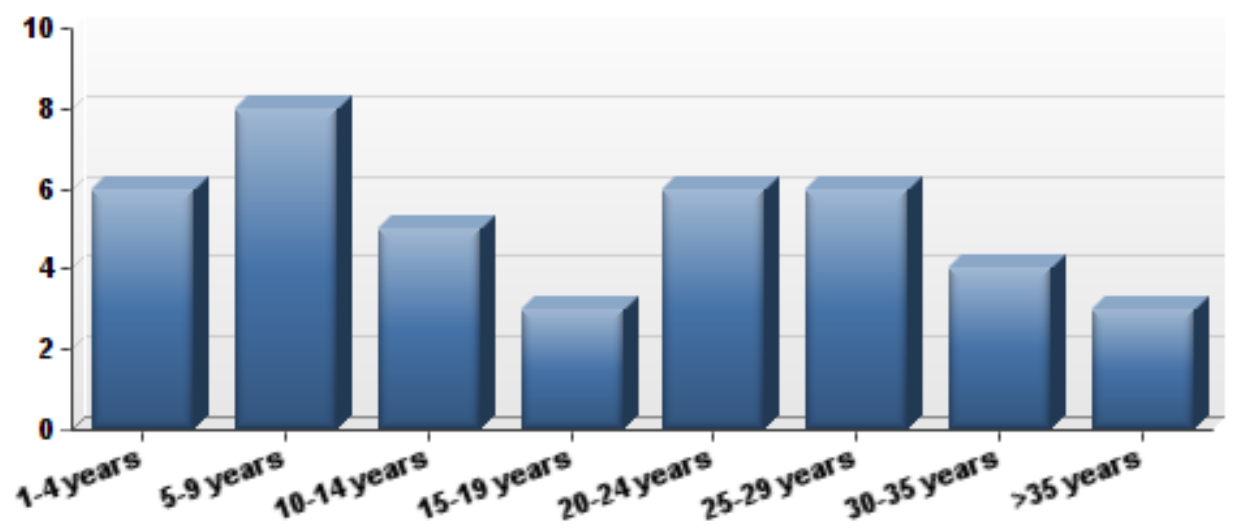

\begin{tabular}{|c|l|l|c|c|}
\hline$\#$ & Answer & & Response & $\%$ \\
\hline 1 & $1-4$ years & 6 & $15 \%$ \\
2 & $5-9$ years & 8 & $20 \%$ \\
\hline 3 & $10-14$ years & & 5 & $12 \%$ \\
\hline 4 & $15-19$ years & & 3 & $7 \%$ \\
\hline 5 & $20-24$ years & 6 & $15 \%$ \\
6 & $25-29$ years & 6 & $15 \%$ \\
7 & $30-35$ years & 6 & $10 \%$ \\
\hline 8 & $>35$ years & & 3 & $7 \%$ \\
\hline
\end{tabular}




\section{Statistic}

Min Value

Max Value

Mean

Variance

Standard Deviation

Total Responses

\section{How many years have you worked in the NICU specialty?}

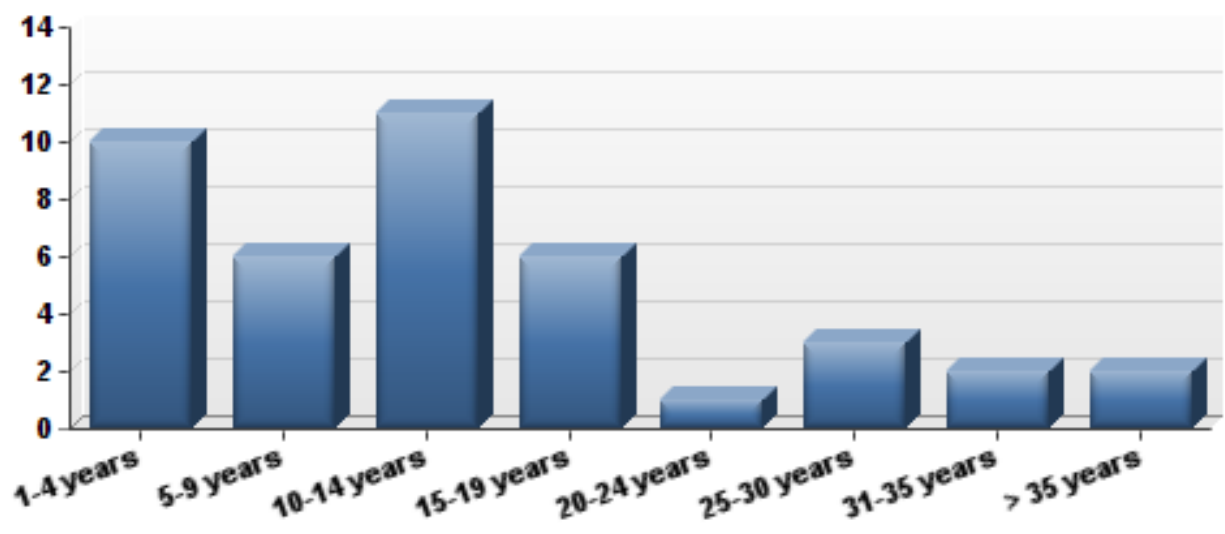




\begin{tabular}{|c|l|l|c|c|}
\hline$\#$ & Answer & & Response & \% \\
\hline 1 & $1-4$ years & & 10 & $24 \%$ \\
\hline 2 & $5-9$ years & & 6 & $15 \%$ \\
\hline 3 & $10-14$ years & & 11 & $27 \%$ \\
\hline 4 & $15-19$ years & & 6 & $15 \%$ \\
\hline 5 & $20-24$ years & & 1 & $2 \%$ \\
\hline 6 & $25-30$ years & $31-35$ years & 3 & $7 \%$ \\
\hline 7 & $>35$ years & Total & 2 & $5 \%$ \\
\hline 8 & & & 2 & $5 \%$ \\
\hline
\end{tabular}

Statistic

Value

Min Value

Max Value

Mean

Variance

4.08

Standard Deviation

2.02

Total Responses 


\section{How often do you use developmental positioning techniques in the NICU?}

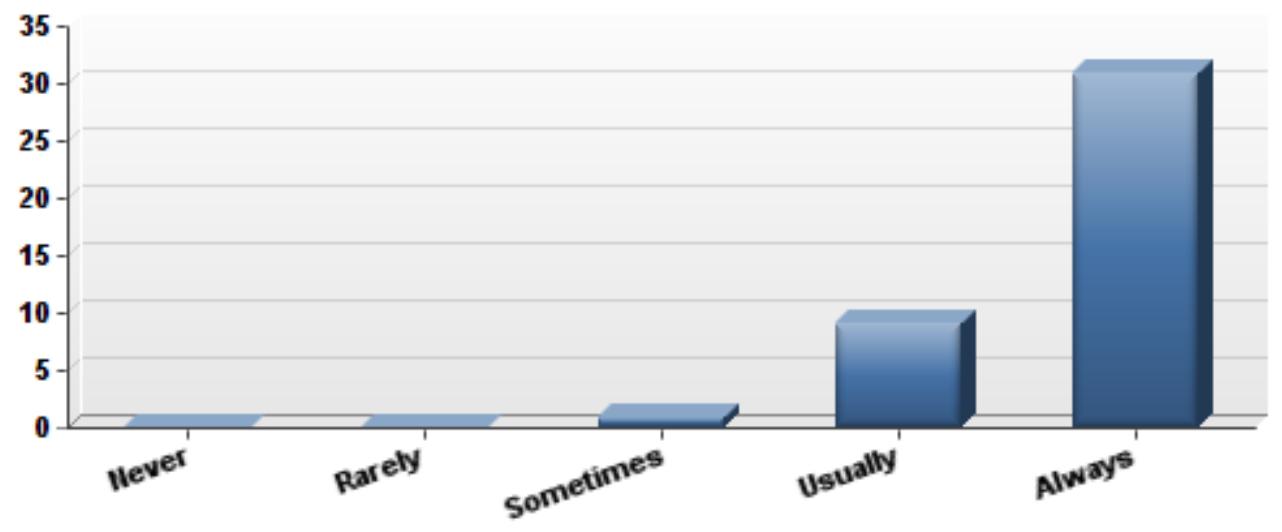

\begin{tabular}{|c|l|l|c|c|}
\hline$\#$ & Answer & & Response & $\%$ \\
\hline 1 & Never & & 0 & $0 \%$ \\
\hline 2 & Rarely & & 0 & $0 \%$ \\
\hline 3 & Sometimes & & 1 & $2 \%$ \\
\hline 4 & Usually & & 9 & $22 \%$ \\
\hline 5 & Always & & 31 & $76 \%$ \\
\hline & Total & & 41 & $100 \%$ \\
\hline
\end{tabular}

Statistic

Value

Min Value

Max Value

Mean

Variance

0.25

Standard Deviation

0.50

Total Responses 


\section{Which developmental positioning devices do you routinely use? Select all that apply.}

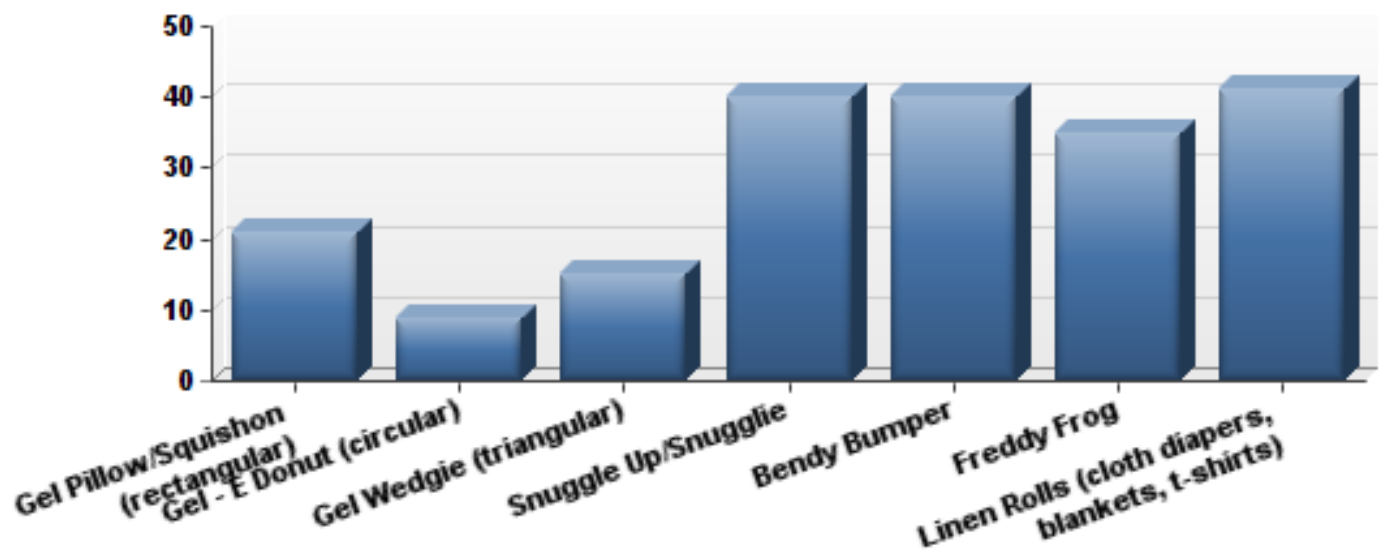

\begin{tabular}{|c|c|c|c|}
\hline$\#$ & Answer & Response & $\%$ \\
\hline 1 & $\begin{array}{l}\text { Gel } \\
\text { Pillow/Squishon } \\
\text { (rectangular) }\end{array}$ & 21 & $51 \%$ \\
\hline 2 & $\begin{array}{l}\text { Gel - E Donut } \\
\text { (circular) }\end{array}$ & 9 & $22 \%$ \\
\hline 3 & $\begin{array}{l}\text { Gel Wedgie } \\
\text { (triangular) }\end{array}$ & 15 & $37 \%$ \\
\hline 4 & $\begin{array}{l}\text { Snuggle } \\
\text { Up/Snugglie }\end{array}$ & 40 & $98 \%$ \\
\hline 5 & Bendy Bumper & 40 & $98 \%$ \\
\hline 6 & Freddy Frog & 35 & $85 \%$ \\
\hline 7 & $\begin{array}{l}\text { Linen Rolls } \\
\text { (cloth diapers, } \\
\text { blankets, t- } \\
\text { shirts) }\end{array}$ & 41 & $100 \%$ \\
\hline
\end{tabular}


Statistic

Min Value

Max Value

Total Responses
Value 


\section{What is your definition of developmental positioning for preterm infants?}

\section{Text Response}

Neutral flexion

My definition of developmental positioning for preterm infants is creating an area that mimics the womb.

Positioning the infant in a way that mimics the womb and promotes self soothing.

Placing the preterm infant in a position similar to the position in utero: Extremities tucked and flexed, back/shoulders rounded, hands to face. May be prone, supine, or side lying.

Positioning them how I like to sleep LOL

To promote natural flexion and increase comfort to facilitate growth and healing

Developmental positioning will aid with preterm infant's growth and development. By proper positioning will provide these infants structural and postural alignment therefore lessening incidence of poor or abnormal posture. Keeping their limbs central or midline helps with comfort ( hands to mouth activity ), conserve calories therefore aid with growth among others .

To mimic uterine positioning to support shaping of the head and support brain and body growth Positioning the infant in a position to facilitate security and correct development of infant. positioning an infant to sleep in a way that will help them grow and promote normal motor development.

to keep the infant in neutral, slightly flexed position with head, shoulders and hips in alignment. proper positioning for pre-term infants impacts brain and musculoskeletal development. head midline, firm boundaries, hips and arms flexed, hips not spread too far out, hands near mouth, face in sniff position

Positioning that keeps them flexed, tucked in, and as close as possible to what their in utero position would likely be.

Fetal positioning that helps promoting growth for preterm infant.

A baby needs hips flexed with legs tucked under. Neck in good natural alignment, usually obtained with a folded diaper. Rotate position every 3-4 hours as told. Also boundaries in place with hands up toward the mouth.

To place in a neutral spine position giving boundaries to have a "stop point" for arms and legs to simulated life in the womb. To keep body in flexion. 
Positioning them in a neutral position that they would naturally be in, if they were still in the womb.

As close to what the baby would be if still in the womb.

Positioning the infant in a way to promote desired and healthy growth and development- both physical and emotional.

Helps calm the infant and aid in their development as they normally would develop in utero.

It's an attempt to address developmental positioning which mimics the uterus and utero.

Any positions that help the baby feel comfortable like they were in the uterus.

Neutral position, flexion, better sleep, calm, look comfortable.

Positioning infants for comfort, supporting brain growth and development with reduced noise, stimulation, allowing for joint and muscle development in proper alignment.

First ROM- turning right to left with support of back, small diaper between the knees- not just prone and back.

Placing infants in flexed, hand to mouth, rounded shoulders.

To position preterm infants wit extremities midline and flexed which will help infants develop appropriately.

Developmentally supportive methods of positioning in normal body position to support natural growth and development, assist with state regulation, position body as it is meant to be- ex. midline neutral flexion of head and all extremities. Avoid arching, extension of extremities, over stretching of joints. Head neutral, midline.

Simulating boundaries like the womb.

Making certain infant is positioned in the most effective and aligned position for optimal development and comfort.

Proper body alignment, comfortable positioning, changing positions with every assessment, head midline in relation to the body, back and shoulders relaxed, flexed position of arms and legs, fetal position.

Emulate the womb.

Flexed and comfortable.

Positioning appropriately to promote correct muscular skeletal development/growth. 
To assimilate as close to positioning as neonate would be in fetal state while in the womb.

Positioning that keeps the legs and arms flexed, similar to "fetal" positing. Use abdominal rolls when prone to flex the knees and hips. Providing head cushioning (gel pillows, frogs, donuts) to prevent positional deformities eg. "toaster heads". Developmental positioning implies that the positioning assists/promotes normal development of the preemie.

Arms, legs flexed position- most like fetal positiong. Prone or supine until late preterm them back to sleep.

providing an environment that mimics the uterus as clos as possible. to decrease stress and promote musculoskeletal growth and strength

to have infant positioned with boundaries; head midline, flexed and midline extremities

\section{Where/how/from whom did you learn about developmental positioning?}




\section{Text Response}

Developmental conferences

I learn about developmental positioning from my preceptor, and for fellow NICU coworkers, and than got more in-depth teaching from Arlene during skills lab.

I learned about developmental positioning starting as a new grad from my preceptors. Over the years I have learned other positioning techniques from coworkers and skills labs.

Nurse preceptors.

During my preceptorship

On orientation as a new grad

Conferences and skills lab at work

Books, mentor when orienting, and Skills lab

It is listed in CPN (our computer charting) as a question, and during orientation it was discussed, but without much detail or information.

orientation evidence based articles

Good Samaritan Hospital Skills lab. Arlene Spilker. Susan Rhodes. LPCH Neuro NICU Course school and visual comfort for the baby

Worked in level III NICU in Texas - had a developmental care committee that presented research at each staff meeting.

During orientation- from preceptors.

From literature, from orientation, and part of routine NICU care.

I come from geriatrics care and know the importance of turning and proper positioning with elderly. Once in NICU I was on Low Birthweight Committee with Jill P. and Lydia C.We worked at that time developing a plan to promote proper age appropriate positioning. It's a bit of a pet peeve with me.

Katherine Jorgenson: Premie for a Day Katherine Jorgenson: Children's Medical Ventures 2 conferences

My fellow NICU nurses. Learn by watching and doing.

Past full time position- from developmental care committee, and outside consultant. 
Staff inservice- watching others.

The nurses orienting me to the unit and skills lab.

Orienting during my normal routine orientation to the unit.

As part of my NICU training some instruction were given. After additional and more thorough instructions were provided by Arlene Spilker at our annual skills lab.

Preceptors, coworkers, and babies/patients.

From job and coworker, book, and journal.

Preceptors, conferences, product reps.

When I worked in other units. Had inservice about 5 years ago in another unit. Pick tips and positioning from nurses.

Kelly Ryan and Arlene Spilker.

I learned it from my preceptors here in the NICE and skills lab. Learned it from demonstration and pictures.

BSN program did thesis on Als theory of neonatal development. Conferences, CEIs, developmental positioning, NICU articles.

Skills labs, demonstration, practice.

NICU-CNS as part of my developmental committee team.

1st job in NJ taught by RNs who precepted.

Coworkers

You.

Staff development.

Educational literature, hands on clinical teaching (skills lab, etc.), self taught also from years of observation of neonates.

From a number of sources: -NIDCAP training at Stanford- emphasized creating an environment/ positioning similar to being in the womb. -Conferences- Company "Children's Medical Ventures" that make the snuggle ups, bendies, etc. at their vendor station. - Gaye Gale: UCSF/Oakland Children's Hospital- she helped design the snugglies for "Children's Medical Ventures" 
Through BSN education and on job training/orientation.

Physical therapy mostly; some is just common sense.

Another hospital in the late 70s. Continued over the years. 


\section{What are the risks of developmental positioning?}

\section{Text Response}

Not sure what the risks are.

If used correctly there shouldn't be any risks to an infant that is on a monitor. Without a monitor there could be risk of suffocation with extra objects in a crib.

Head molding from too frequent positioning on one side or one position; Tight hips, knees, ankles from maintaining tucked positioning without changing position to allow for occasional extension and ROM.

Misshaped head, contractures, desats, prolonged recovery

Abnormal or poor posture. Delays on gross and fine motor skills.

\section{NONE?}

Repetitive incorrect positioning can cause abnormal physical development to infant, and diminish infant's comfort.

Loss of an ETT or PIV

None

Poor development of muscle tone, tightness in hips/neck. torticollis, hip dysplasia, delayed walking, sitting

Doing it incorrectly may cover/hide IV sites.

Leg/hip dislocation, abnormal shape for head, and stiffen neck.

The baby grows up with many issues (eg. their shoulders too arched back, their feet pronate).

When done correctly- no risk. When done incorrectly- torticollis of the neck, shoulder pain, arms and legs unable to flex, feet permanently turned in.

None, it helps them in all aspects of their growth and development.

Not being able to see IVs well.

The gel pad apparently had some bacterial growth. Also the parents may assume extra linen and rolls are appropriate in an open crib when they take baby home and baby could suffocate.

If not done properly can do the infant long and short term harm.

None to my knowledge. 
Causing problem to airways. If it's wrong, misshape of body part.

Flat head.

Ventilator tubing, IV boards, lack of positioning tools, noise in critical care units, lack of parental contact.

First pressure points (but rare in our unit). Second- "The Intubation Head". Third- baby will not turn head to left. Fourth: Baby get stiff. Five: When the baby can tolerate it massage to relax the baby.

I don't know.

Putting the babies in an inappropriate position that does not promote flexion or a "normal" position.

Overheating baby (if no bunting is used, then used- it will raise baby's temp- easy to monitor). Soft cushions not to be near nose/mouth- risk of suffocation/ brady if not monitored closely.

Potential stiffness or decrease ROM if not done appropriately with position change.

Limited position.

Extubation, lung collapse if in some positions too long, if poorly positioned- ears being bent.

Collapse lungs and toaster head.

SIDS when not in hospital setting. Unintentionally teaching parents to mimic at home.

Mal development- causing physical/ developmental problems that require PT/OT at a later date to correct.

Not sure I can thinkg of any unless it interferes with medical care but in my practice there are always things you can do developmentally.

Not a fan of the danny slings as these cause frog-like deformities of the arms and legs due to prone positioning, especially if abdominal rolls are not used to maintain flexion. Infants sometimes need 1) extensive physical therapy later on to improve flexion in limbs; 2)helmets to fix head deformities.

Contractures/ muscle shortening, poor circulation in no ROM/ stretching done.

Need to guard endotracheal tubes and IV lines

increased oxygen needs longer skull physical/developmental delays 


\section{Identify any barriers to implementing developmental positioning?}

\section{Text Response}

Lack of education

Some barriers include infant birth defects, PIV's, umbilical lines, EET.

Barriers include lack of positioning aids and staff that are not educated in developmental positioning.

Positioning aids not available Physical anomalies

Infant conditions such as gastrochisis, omphalocele, etc. Occationally the type of ventilator and/or umbilical lines can prohibit developmental positioning.

Hospital budget

Not enough understanding on the importance of developmental positioning in the practice. No supply /aids available for use.

Lack of developmental \& supportive positioning devices, IV sites, habit of using prone positioning routinely (for better milk absorption), lack of teaching importance of developmental positioning.

Amount of tubes, invasive treatments,such as ventilated or CPAP patients. Other tubes and drains. Physical issues - respiratory compromise, painful procedures, lack of time.

Lines and tubes (UAC, UVC, Vent, PIV, PICC)

Lack of knowledge. Lack of gel pillow or positioning devices. PIV in a delicate position lack of knowledge and skills.

our devices (CPAP, IVs UVCs/UACs) parents not understanding the importance and unwrapping babies

Lack of products. Lack of knowledge about alternative products.

Respiratory distress and indigesting.

We need the gel pillows back. Just nursing compliance. I will have them all positioned and the next shift pulls it all out, especially gel pillows when we had them.

IV and lines. Especially IV in foot/ankle. Ignorance of health care providers and parents.

Lack of supply of positioning devices, medical equipment (ETT, IVs, UVCs...) 
Time, education, supplies.

Lack of supplies, lack of education on proper use of equipment.

Lack of positioners or linens on unit, lack of time, certain diagnosis (such as gastroschesis, etc) that might make positioning difficult.

Lack of knowledge in proper positions (I have attemted googling resources to no avail).

Refresher training and available materials provided or not by the hospital.

Medical equipment, baby's movement.

None.

New staff education.

Not right equipment. Other RNs ideas. The other critical point some babies are unstable on their back.

Medical devises, such as, PIV, umbilical lines, ETT, chest tubes.

Not having enough clean, new, appropriate size aids.

Lack of education of staff in what developmental positioning can do: - ex. promotes comfortbaby less fussy - ex. normal development- less PT therapy needed later - ex. normal head shapeeasier for baby to bottle/ BTB

Not having available positioning aids or too many different ones.

Nurse practice.

Not having supplies, not feeling comfortable, unstable babies who can't tolerate a lot of movement, needing to visualize IV and devices.

*Supplies not available* Equipment (vents, CPAP, PIV, UAC, UVC)

Parents perceptions i.e. "My baby want to be free \& kick."

Staff knowledge, lack of resources, education, poor staffing, people being in a hurry, not always a priority.

To be truthful, lack of want/laziness, then lack of knowledge and teaching and supplies.

Orders to use dannysling, HOB 45 degrees. IV lines. Although back to sleep positioning for infants in open cribs is now the standard of practice, many infants end up with flat spots on the back of their heads (is this more common in preemies than term infants? Late preterms will have 
softer skill bones than at 40 weeks.)

Lines, ETT, CT, POST-OP, certain diagnosis.

not enough supplies available to utilize positioning

positional aids not available - gel pillows, gel mattress, etc. make it easier, but i realize w can optimize with other items 


\section{What are the benefits of developmental positioning?}

\section{Text Response}

Positive long term muscle development and neurodevelopment

Benefits of developmental positioning include better rest for the infant, neural development, less need for physical therapy post discharge.

Developmental positioning promotes rest, comfort, and self soothing. These things allow the infant to grow and develop optimally.

Improved cardio-respiratory stabilty Decreased FIO2 needs Improved body temperature stability Improved neuro-muscular development Improved GI function/toleration of feedings Improved growth

Lower oxygen reqirements, fewer episodes of desats/apnea/heart dips, meeting long term developmental milestones, providing confidence in the parents regarding your nursing ability by visualizing the comfort of their child and maintenance of their bedside, etc.

Faster recovery time, proper growth development, happy baby

Aids in the growth and development of premies ... Providing comfort and conserve calories.

Closer to normal body and brain growth and development, infant comfort, frequently a decrease in apnea,bradycardia, desaturations.

Patient comfortably positioned and calm. Promotes optimal developmental growth.

Helps infants grow appropiately.

Shorter hospital stays overall. Infant with better ability to breathe, eat and has better tone.

proper brain and musculoskeletal developement

meeting developmental milestones, good muscle tone, normal head shape

Calmer babies. Better physical comfort and development.

Promote growth (gain weight).

Proper body alignment, development.

Less long term muscle problems-such as straight arms, shoulders and pectorial muscles tight. Better pain control, better sleep. Better O2 needs.

Better growth, less risk muscle injury (stiffness...), improvement in status. 


\section{Shorter NICU stay and better outcomes.}

More restful sleep, better growth.

Improved musculoskeletal development, calms agitated infant, sense of security for infant, improve digestion.

The infant will develop appropriately with how they would in utero. Helps calm the infant so they can mature appropriately while in the NICU.

Promotes a more natural transition from utero to NICU, decreases stress and promotes healthy hips and head shape.

Baby's resting, growing.

Better feeding tolerance, improving respiratory status, baby stay calm, VS stable, less spells, less complication, less stress.

Less need for PT, reduced joint pain, better brain development, increase learning ability.

Relaxed babies, less requires of F O2 (have seen it). If a baby has had surgery give them pain medicine and turn them and do ROM. Lack of pain medicine in this unit. Example- babies with CT's or placement of them.

Better brain development, happier babies (happier nurse, parents), less physical therapy when discharged.

To help the babies feel secure and comfortable and help them as best as possible develop normally outside the womb.

State regulation, increased comfort, deeper sleep state, normal body development, round head shape which assists later with head control/feeding/acceptance of baby into family, decrease need for PT, decrease need for head caps to remold head, improve growth and development.

Relaxed infants, better growth and development, better temperature regulation possibly.

Growth/ development

Infant has better muscle development, decrease in misshaped heads, better sleep periods.

Prevents frog legs (contractures/ hip displaysia). Keeps baby comfortable and calm, uses less O2.

More restful longer lasting periods of sleep. Minimize need for physical therapy later to correct poor positioning techniques. Decrease O2 need..

Correct growth and development. 
Calm state of neonatal muscle tone and stretching prevents maldevelopment of skeletal muscles.

Prevent positional deformities of limbs and head.

Promotes optimal musculo-skeletal development and ROM.

decreased stress; decreased FiO2; shorter hospitalization

babies development more normalyl if environment mimics the intrauterine environment better sleep and growth patterns decreased long term developmental and physical delays better outcomes overall 